\title{
Aggressive pancreatic ductal adenocarcinoma in mice caused by pancreas-specific blockade of transforming growth factor- $\beta$ signaling in cooperation with active Kras expression
}

\author{
Hideaki Ijichi, ${ }^{1}$ Anna Chytil, ${ }^{1,4}$ Agnieszka E. Gorska, ${ }^{1,4}$ Mary E. Aakre, ${ }^{1,4}$ Yoshio Fujitani, ${ }^{2,3,5}$ \\ Shuko Fujitani, ${ }^{2,3,6}$ Christopher V.E. Wright, ${ }^{2,3}$ and Harold L. Moses ${ }^{1,4,7}$ \\ ${ }^{1}$ Department of Cancer Biology, Vanderbilt University, Nashville, Tennessee 37232, USA; ${ }^{2}$ Cell and Developmental Biology, \\ Vanderbilt University, Nashville, Tennessee 37232, USA ${ }^{3}$ Vanderbilt University Program in Developmental Biology, \\ Vanderbilt University, Nashville, Tennessee 37232, USA; ${ }^{4}$ The Vanderbilt-Ingram Comprehensive Cancer Center, \\ Vanderbilt University, Nashville, Tennessee 37232, USA
}

Pancreatic ductal adenocarcinoma (PDAC) is an almost uniformly lethal disease in humans. Transforming growth factor- $\beta$ (TGF- $\beta$ ) signaling plays an important role in PDAC progression, as indicated by the fact that Smad4, which encodes a central signal mediator downstream from TGF- $\beta$, is deleted or mutated in $55 \%$ and the type II TGF- $\beta$ receptor (Tgfbr2) gene is altered in a smaller subset of human PDAC. Pancreas-specific Tgfbr2 knockout mice have been generated, alone or in the context of active Kras (Kras ${ }^{\text {G12D }}$ ) expression, using the Cre-loxP system driven by the endogenous Ptf1a (pancreatic transcription factor-1a) locus. Pancreas-selective Tgfbr2 knockout alone gave no discernable phenotype in 1.5 yr. Pancreas-specific Kras ${ }^{G 12 D}$ activation alone essentially generated only intraepithelial neoplasia within $1 \mathrm{yr}$. In contrast, the $T g f b r 2$ knockout combined with Kras ${ }^{G 12 D}$ expression developed well-differentiated PDAC with $100 \%$ penetrance and a median survival of 59 d. Heterozygous deletion of Tgfbr2 with $\mathrm{Kras}^{\mathrm{G1}}{ }^{\mathrm{DD}}$ expression also developed PDAC, which indicated a haploinsufficiency of TGF- $\beta$ signaling in this genetic context. The clinical and histopathological manifestations of the combined Kras ${ }^{G 12 D}$ expression and Tgfbr2 knockout mice recapitulated human PDAC. The data show that blockade of TGF- $\beta$ signaling and activated Ras signaling cooperate to promote PDAC progression.

[Keywords: Kras; pancreas-specific knockout; pancreatic ductal adenocarcinoma; Ptfla; TGF- $\beta$; type II TGF- $\beta$ receptor]

Supplemental material is available at http://www.genesdev.org.

Received July 28, 2006; revised version accepted September 27, 2006.

Pancreatic cancer is one of the leading causes of cancer death in many countries, and also is one of the most lethal diseases, with a $<5 \% 5$-yr survival rate (Warshaw and Fernandez-del Castillo 1992; Hezel et al. 2006; Jemal et al. 2006). Poor survival is likely because most of the patients are already at an unresectable stage when diagnosed. Moreover, even with a successful resection, most patients have recurrence within a year, and the tumors

Present addresses: ${ }^{5}$ Juntendo University, Tokyo 113-8421, Japan; ${ }^{6}$ Osaka University, Osaka 565-0871, Japan.

${ }^{7}$ Corresponding author.

E-MAIL hal.moses@vanderbilt.edu; FAX (615) 936-1790.

Article is online at http://www.genesdev.org/cgi/doi/10.1101/gad.1475506. are resistant to all forms of conventional therapies. Since the most common form is pancreatic ductal adenocarcinoma (PDAC), to establish a good animal model that recapitulates aggressive full-blown human PDAC is of high importance for a better understanding of this disease, and for development of better means of early detection and treatment.

Previous histological and molecular studies have suggested a model of disease evolution through a preinvasive state, termed pancreatic intraepithelial neoplasia (PanIN), along with accumulating specific genetic alterations (Hruban et al. 2001). An activating point mutation of the Kras proto-oncogene is found in PanIN lesions and with increasing frequency at later stages, and in $>90 \%$ of 
invasive PDAC. Kras mutation is thought to be a tumorinitiating event (Klimstra and Longnecker 1994; Rozenblum et al. 1997). Genetic and epigenetic inactivations of tumor suppressor genes, including $p 16^{I N K 4 a}, p 53$, and Smad4 (DPC4), increase in frequency in progressively higher PanIN stages, and are found in $\sim 90 \%, 75 \%$, and $55 \%$, respectively, of invasive PDACs (Rozenblum et al. 1997). Therefore, activation or inactivation of these signaling pathways seems to have a crucial role in PDAC formation.

Recently, genetically engineered mouse PDAC progression models were obtained by pancreas-specific conditional activation or knockout of those clinically relevant PDAC-related genes, using the promoters Pancreatic and duodenal homeobox gene $1(P d x 1)$ or pancreatic transcription factor 1 a (Ptf1a, or p48). Pdx1 and Ptf1a are both expressed at the pancreas epithelial progenitor stage and are essential for pancreas development and differentiation (Offield et al. 1996; Kawaguchi et al. 2002). The Pdx1-Cre;LSL-Kras G12D/+ or Ptf1 $a^{\text {cre/+ }}$;LSL-Kras ${ }^{G 12 D /+}$ model (Hingorani et al. 2003), both of which excise the stop codon between loxP sites in the LSL-Kras ${ }^{G 12 D}$ allele, generate physiological levels of expression of the constitutively active mutant Kras (Kras ${ }^{G 12 D}$ ) transcript from the native Kras promoter. Although all three epithelial lineages of the pancreas (ductal, acinar, islet) have a genetic modification in these mice, they developed pancreatic ductal neoplasms, which recapitulated human PanIN lesions. The lesions slowly progress further into advanced PDAC with a median survival of 15 mo (Hingorani et al. 2005), suggesting again that the Kras activation is a tumor-initiating event and that specific accelerative events are required for human PDAC progression. Based on this LSL-Kras ${ }^{G 12 D}$ model, three representative studies of invasive PDAC models were reported (Aguirre et al. 2003; Hingorani et al. 2005; Bardeesy et al. 2006). In one model-Kras ${ }^{G 12 D}$ expression plus Ink4a/Arf allele knockout (Pdx1-Cre;LSL-Kras ${ }^{G 12 D /+}$; Ink 4a/Arflox/lox $)$ - there was highly invasive PDAC with a median survival of 8 wk (Aguirre et al. 2003). There were, however, relatively few macrometastatic lesions. In addition, one-third of the PDAC was accompanied by spindle cell or sarcomatoid histology, which is an infrequent phenotype in human PDAC. Pdx1-Cre; LSL-Kras ${ }^{G 12 D /+}{ }^{2} L S L-T r p 53^{R 172 H /+}$, which had Kras ${ }^{G 12 D}$ expression plus Trp53 inactivation each driven by their respective native promoters, demonstrated highly metastatic PDAC with a median survival of 5 mo (Hingorani et al. 2005). The histology exhibited differentiated ductal adenocarcinoma, recapitulating human PDAC, but the survival was much longer than Pdx1-Cre;LSL-Kras ${ }^{G 12 D /+}$; Ink $4 a / A r f^{l o x} /$ lox . The latest study comparing various combinations of Pdx1-Cre;LSL-Kras G12D/+ with $\mathrm{p16}^{-/-}$, Ink4/ Arf lox/lox , and $p 53^{\text {lox/lox }}$ showed PDACs with various tumor latency and various histological distribution of differentiated adenocarcinoma, anaplastic carcinoma, and sarcomatoid tumor, depending on the type of knockout (Bardeesy et al. 2006). Among them, homozygous mutants of either $p 16^{I N K 4 a}$ or $p 53$ showed much shortened tumor latency and a greater frequency of undifferentiated histol- ogy. Mice with a wild-type $p 16^{I N K 4 a}$ allele in their genotype showed a tendency to have differentiated PDAC histology. These published models formed extra-pancreatic tumors as well because Pdx1 is also expressed in extrapancreas regions (Offield et al. 1996); sometimes those tumors were aggressive, which suggested that a more specific pancreatic mouse model might be preferable.

Among the clinically relevant PDAC-related tumor suppressor pathways described above, the transforming growth factor- $\beta$ (TGF- $\beta$ )-Smad signaling pathway still remains to be investigated in the context of active Kras expression for modeling human PDAC. TGF- $\beta-S m a d$ signaling is well known to have growth inhibitory effects on epithelial cells, among its multiple physiological functions (Miyazono et al. 2000). Loss of this signaling might cause an escape of cells from appropriate growth regulation, which would result in tumor formation in a variety of organs. Smad4, which encodes a central signal mediator downstream from the TGF- $\beta$ receptors, is frequently inactivated in invasive human PDAC as described above (Hahn et al. 1996), and it is by far the most frequent among human sporadic cancers. The type II TGF- $\beta$ receptor $(T g f b r 2)$ gene is mutated or deleted in a smaller subset of human PDAC (Goggins et al. 1998). Together, these findings suggested that Smad4 inactivation or impaired TGF- $\beta$ signaling might be contributing to the highly invasive and metastatic PDAC cell characteristics.

On the other hand, TGF- $\beta$ signaling is considered to enhance tumor progression in the later stages (Derynck et al. 2001). With regard to the pancreas, TGF- $\beta$ isoforms 1,2 , and 3 are highly expressed in human PDAC tissue, a feature that is correlated with poor prognosis (Friess et al. 1993), which suggests the tumor-promoting effect of this cytokine. TGF- $\beta$ signaling is also important in pancreas development. It is reported that TGF- $\beta 1$ promotes development of endocrine cells and disrupts epithelial branching and acinar formation in vitro (Sanvito et al. 1994), while dominant-negative Tgfbr2 transgenic mice showed increased proliferation of acinar cells and severely perturbed acinar differentiation in vivo (Bottinger et al. 1997).

We have conditionally inactivated Tgfbr2 using Cre/ loxP technology (Chytil et al. 2002) and also reported that Tgfbr2 knockout in the mammary gland epithelia in addition to polyoma virus middle $\mathrm{T}$ antigen expression shortened tumor latency and enhanced lung metastasis (Forrester et al. 2005), which indicates a predominant tumor suppressor effect of TGF- $\beta$ signaling on breast cancer progression. Here, we report the effect of Tgfbr2 knockout on pancreas development, and further on PDAC progression in the context of active Kras expression. In contrast to the dominant-negative Tgfbr2 transgenic mice study, pancreas epithelium-specific Tgfbr2 knockout revealed no obvious effect on normal pancreas development. Tgfbr2 knockout with active Kras expression dramatically promoted PDAC progression from mouse PanIN (mPanIN) lesions, and the PDAC recapitulated the human disease extremely well. These findings indicate that disrupted TGF- $\beta$ signaling and activated 
Ras signaling might contribute synergistically to PDAC formation and that this model is a most promising avenue for attacking this difficult human disease.

\section{Results}

Normal pancreas development in the pancreas epithelium-specific Tgfbr2 knockout mice

To investigate the effect of TGF- $\beta$ signaling in pancreas development and disease, we first generated pancreas epithelium-specific Tgfbr2 knockout mice by crossing the Ptf1a $a^{\text {cre/+ }}$ mice (Kawaguchi et al. 2002) with the Tgfbr2 flox/flox mice (Chytil et al. 2002), resulting in the genotype Ptf1 $a^{\text {cre/+}} ;$ Tgfbr $2^{\text {flox/flox }}$. By using the Ptf1a promoter, the Cre recombination and consequent Tgfbr2 knockout were expected to take place in all three pancreas epithelia lineages: duct, acinar, and islet cells. While the $\mathrm{Tg}_{\mathrm{fbr2}} \mathrm{C}^{--}$mice were embryonic lethal (Oshima et al. 1996), the Ptf1 $a^{\text {cre } /+} ;$ Tgfbr2 ${ }^{\text {flox/flox }}$ mice were born at the expected frequency. PCR analysis de- monstrated the recombined allele of the Tgfbr2 gene in the pancreas, and Cre-recombinase expression was uniformly detected in the acinar, ductal, and islet cells by X-gal staining of the mice further crossed with Rosa26 reporter mice (genotype: Ptf1 $a^{\text {cre/+}} ; \mathrm{Tgfbr}^{\text {flox/flox }}$; Rosa26r) (Soriano 1999), which confirmed the expected Tgfbr2 knockout in a pancreas epithelium-specific manner (Fig. 1A-C).

The pancreas of Ptf1 $a^{\text {cre/+ }} ; \mathrm{Tg} f b r 2^{\text {flox/flox }}$ mice appeared very normal (Fig. 1D). We analyzed the expression of islet cell markers, glucagon, insulin, somatostatin, pancreatic polypeptide, and the acinar cell marker amylase, which revealed that somatostatin-positive cells were more frequently observed in the Tgfbr2 knockout mice at the 1-d and 7-wk stages with statistical significance $(p<0.01)$. However, this difference disappeared by $12 \mathrm{wk}$ of age, and other markers showed no difference between the knockout and control pancreas (Fig. 1E). Glucose tolerance tests and body weight monitoring also showed no significant changes compared with the controls (data not shown).

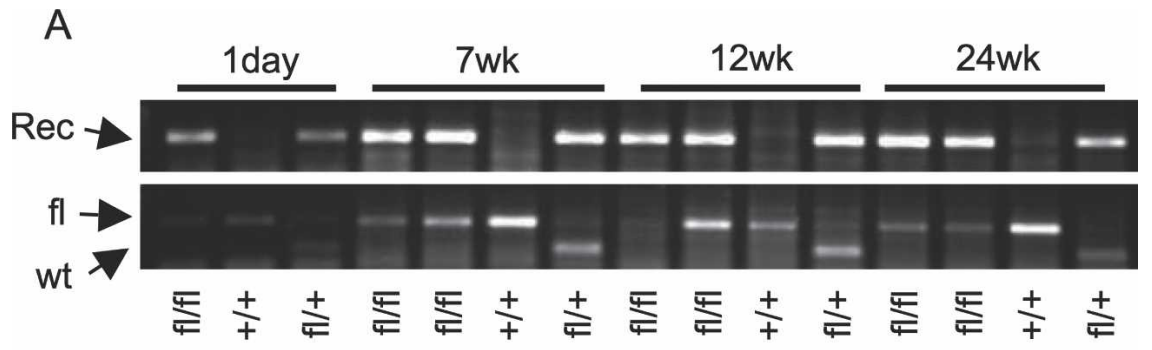

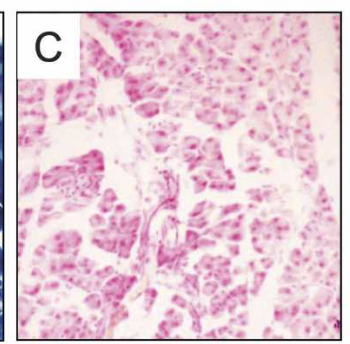

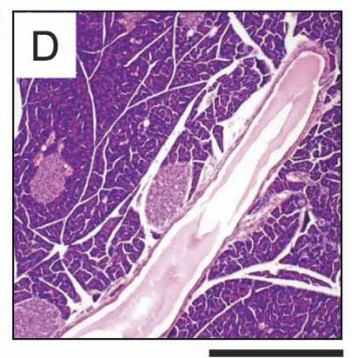

E

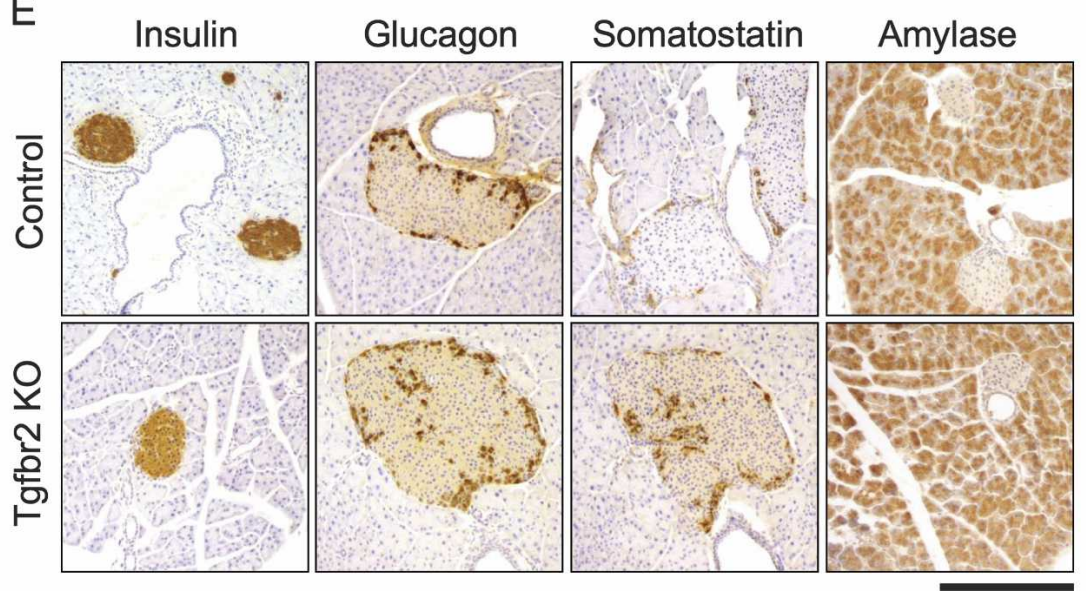

Figure 1. Normal pancreas development in Tgfbr2 knockout mice. (A) PCR detected Tgfbr2 allele recombination in the pancreas tissues of 1-d to 24-wk-old mice. (Top) PCR to detect Tgfbr2 allele recombination. The recombined allele was detected in the Ptf $1 a^{\text {cre } /+} ;$ Tgfbr $2^{\text {flox/flox }}$ and

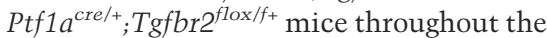
ages examined. (Bottom) Genotyping PCR to detect floxed and wild-type Tgfbr2 alleles. Some floxed alleles appeared to be diminished in those mice that showed the allele recombination. (Rec) Recombined allele; (fl) floxed allele; (wt) wild-type allele of Tgfbr2 gene; (fl/fl) Ptf1 $1 a^{\text {cre/+}} ; \mathrm{Tg}_{\mathrm{fbr}} \mathrm{flox}^{\text {flflox }}$ mice; (fl $/+)$ Ptf1 $a^{\text {cre } /+} ;$ Tgfbr2 $2^{\text {flox } / f+}$ mice; $(+/+)$ $T g f b r 2^{\text {flox/flox }}$ mice. $(B, C) \beta$-Galactosidase in situ staining. Cre recombination was homogeneously observed all through the pancreas of Ptf1 $a^{\text {cre } /+}$; $T g f b r 2^{\text {flox/flox }}$; Rosa26r mice $(B)$, but not in that of $T g$ fbre ${ }^{\text {flox/flox }}$; Rosa26r mice $(C)$. (D) H\&E staining of 1.5-yr-old pancreas of the Ptf1 $a^{\text {cre } /+} ; \mathrm{Tgfbr}^{\text {flox } / \text { flox }}$ mouse. The pancreas was normally developed and has no abnormal findings in Tgfbr2 knockout mice. (E) Immunohistochemistry of endocrine and exocrine pancreas markers at $7 \mathrm{wk}$ of age. Insulin, glucagon, and amylase staining showed no difference. Somatostatin expression was more prominent in the Tgfbr2 knockout mice at this stage. (Control) Tgfbr2 flox/flox mice; (Tgfbr2 KO) Ptf1 $a^{\text {cre/+ }} ;$ Tgfbr2 ${ }^{\text {flox/flox }}$ mice. Bars: $B, C, E 250 \mu \mathrm{m} ; D, 500 \mu \mathrm{m}$. 
Ijichi et al.

Thus, the knockout of Tgfbr2 had only subtle effects on pancreas development and the mice have shown no phenotype up to $18 \mathrm{mo}$. The apparently normal pancreas in the Ptf1a $a^{\text {cre/+ }} ;$ Tgfbr2 ${ }^{\text {flox/flox }}$ mice indicated that the blockade of TGF- $\beta$ signaling in the pancreatic epithelium was insufficient to initiate pancreas tumor formation. Other proto-oncogene activation might be required for spontaneous tumor initiation.

\section{Knockout of Tgfbr2 rapidly promotes mutant Kras-induced PanIN progression to ductal adenocarcinoma}

The Pdx1-Cre;LSL-Kras ${ }^{G 12 D /+}$ or Ptf1a ${ }^{\text {cre/+}} ;$ LSL-Kras ${ }^{G 12 D /+}$ mice have been reported to have mPanIN lesions as early as at 2 wk of age, but most of the lesions did not progress into advanced cancer within $1 \mathrm{yr}$ (Hingorani et al. 2003). We crossed the LSL-Kras ${ }^{G 12 D /+}$ mice with our Tgfbr2 knockout mice and generated mice of the genotype $\mathrm{Ptf1}^{\mathrm{cre} /+} ;$ LSL-Kras ${ }^{\mathrm{G12D/+}} ; \mathrm{Tgfbr} 2^{\text {flox/flox }}$. These mice had active Kras expression plus Tgfbr2 knockout both in a pancreas epithelium-specific manner.
These mice, which were obtained at the expected Mendelian frequency at birth, began to demonstrate abdominal distension at $\sim 6-7$ wk of age, which allowed us to "diagnose" their pancreatic tumor. The distension was due to ascites and the tumor itself, which was firm and palpable through the skin. The mice frequently demonstrated weight loss, bloody ascites, and sometimes jaundice, and were sacrificed when they appeared to be in distress; some died suddenly. The median survival was $59 \mathrm{~d}$ (8.4 wk) (Fig. 2A-C; Supplementary Table 1). These symptoms recapitulate well those frequently found in human PDAC. No animals with other genotypes showed any symptoms at this stage, except for one case $\left(P_{t f 1} a^{\text {cre } /+} ;\right.$ LSL-Kras ${ }^{G 12 D /+} ;$ Tgfbr $\left.2^{\text {flox/++}}\right)$ that had a cystic dilatation of the obstructed main pancreatic duct. A Kaplan-Meyer curve showed a dramatically shortened

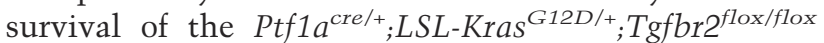
with statistical significance $(p<0.001)$ (Fig. 2A).

The mice were dissected when they became distressed, mostly at $7-10 \mathrm{wk}$ of age. The Ptf1 $a^{\mathrm{cre} /{ }^{+}} ; \mathrm{LSL}-$ Kras $^{G 12 D /+} ;$ Tgfbr2 ${ }^{\text {flox/flox }}$ tumor uniformly occupied the whole pancreas and was irregularly shaped with a homo-
Figure 2. Kras ${ }^{G 12 D}$ expression plus $T g f b r 2$ knockout developed aggressive pancreatic tumors. (A) Kaplan-Meyer curve. Ptf1 ${ }^{\text {cre/ }}$; LSL$\mathrm{Kras}^{\mathrm{G12D/+}} ; \mathrm{Tg} f \mathrm{fbr} 2^{\text {flox/flox }}$ mice $\left(\right.$ Kras $+\mathrm{Tg} f$ br $2^{\mathrm{KO}}$ ) showed a dramatically shortened survival (median survival: 59 d). Ptf1 $a^{\text {cre } /+} ;$ LSL-Kras ${ }^{G 12 D /+}$; Tgfbr $2^{f l o x /+}$ mice $\left(\right.$ Kras $\left.+\mathrm{Tg} f b r 2^{L /+}\right)$ also showed a shortened survival compared with the controls after $200 \mathrm{~d}$. The control group includes the genotypes of LSL-Kras ${ }^{G 12 D /+} ;$ Tgfbr $2^{\text {flox/flox }}$,

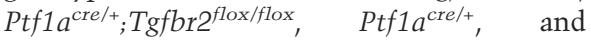
$\mathrm{Ptf1}^{\mathrm{cre} / \mathrm{H}} ; \mathrm{LSL}-\mathrm{Kras}^{\mathrm{G12D/+}}$. $(B, C)$ Gross images of the pancreatic tumor from $P t f 1 a^{c r e /+}$; $L S L$ $\mathrm{Kras}^{\mathrm{G} 12 \mathrm{D} /+} ; \mathrm{Tg} f \mathrm{fb} 2^{\text {flox } / \text { flox }}$ mice. The abdomen was distended due to the tumor (arrowhead) and ascites. (B) Note the bloody ascites in this mouse. The tumor (arrowhead) occupied the entire pancreas and compressed adjacent organs. $(C)$ Note the apparent jaundice in this mouse. (D) PCR detected recombination of the $L S L-K r a s^{G 12 D}$ and floxed Tgfbr2 alleles in a pancreas-specific manner. (Rec) Recombined allele; (wt) wild-type allele. The genotypes of mice are K133, K59, K131, K143: Ptf1 ${ }^{\text {cre } /+} ;$;SL-Kras ${ }^{G 12 D /+} ;$ Tgfbr2 ${ }^{\text {flox/flox }}$; K127: Ptf1 $a^{\text {cre } /+}$;LSL-Kras ${ }^{G 12 D /+}$; K130: Ptf1a ${ }^{\text {cre/+}}$; Tgfbr2flox/flox; $\quad$ K129: LSL-Kras ${ }^{\text {G12D/+} ;}$; Tgfbr2flox/flox; K125: wild-type. (P) Pancreas; (L) liver.
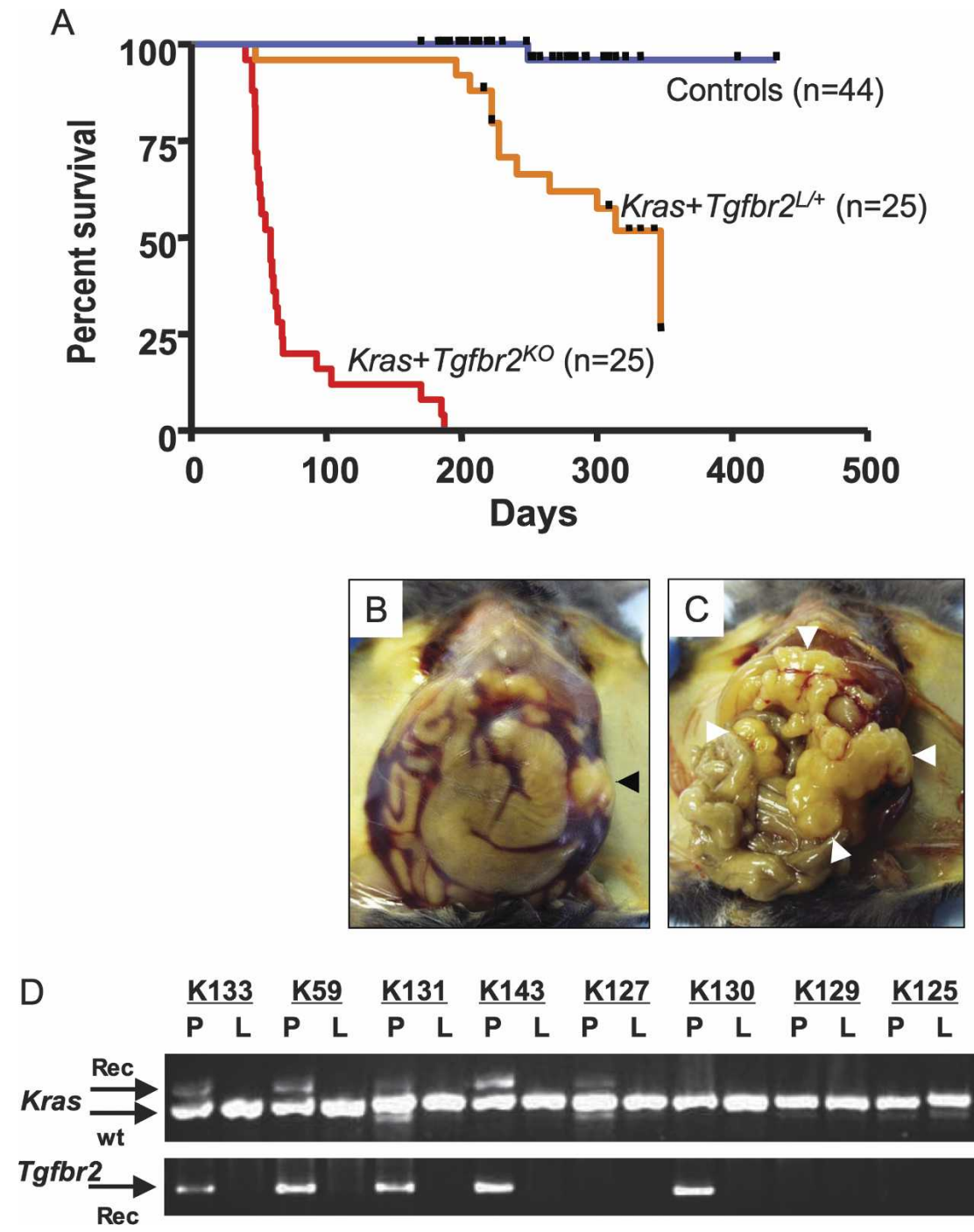
geneous white and firm appearance (Fig. 2B,C). No normal pancreas tissue was seen macroscopically. The duodenum loop was compressed by the tumor, resulting in obvious duodenal and gallbladder dilatation. Splenomegaly was also frequently observed. At this stage, the

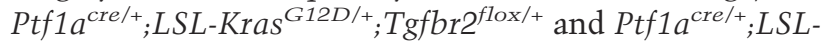
$\mathrm{Kras}^{\mathrm{G} 12 \mathrm{D} /+}$ mice showed only single or a couple of 1-mm-sized nodules, if any, which were also white and firm, while the vast majority of the pancreas still appeared normal. The other genotype pancreases (LSL-

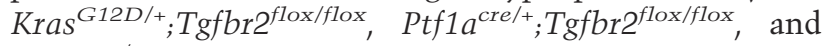
Ptf $1 a^{c r e /+}$ | showed no abnormal appearance. In those pancreatic tissues, the recombined alleles of Kras and Tgfbr2 genes were detected as expected according to the genotype, while the nonpancreas tissue (liver), a negative control, showed no recombination (Fig. 2D).

Upon microscopic examination, the Ptf $1 a^{\mathrm{cre} /{ }^{+}}$; LSL$\mathrm{Kras}^{\mathrm{G12D/+}}$ mice demonstrated mPanIN lesions as reported previously (Hingorani et al. 2003) within a large amount of normal pancreas that contained well-organized acinar, ductal, and islet tissue (Fig. 3A). The $\mathrm{Ptfla}^{\mathrm{cre} /+}$;LSL-Kras ${ }^{\mathrm{G} 12 \mathrm{D} /+} ; \mathrm{Tg} f b r 2^{\text {flox/+ }}$ mice showed similar histology. However, both genotypes showed no PDAC lesions that had grown beyond the basement membrane at the $7-10$-wk stage. The Ptf $1 a^{\text {cre/+ }} ; L S L$ $\mathrm{Kras}^{\mathrm{G12D/+}} ; \mathrm{Tgfbr} 2^{\text {flox/flox }}$ tumors exhibited uniformly well-differentiated glandular architecture $(n=25)$, which occupied the entire pancreas, resulting in almost complete loss of normal pancreatic tissue. The carcinoma cells frequently showed nuclear atypia and invasion beyond the basement membrane (Fig. 3B-D). The nascent invasion of tumor cells into the stroma was also revealed by pan-cytokeratin immunostaining (Fig. 3E). Carcinoma cells showed positive ductal markers, CK19 and mucin (Fig. 3F,G), and were negative for the acinar and islet marker, amylase, and insulin (data not shown), indicating ductal adenocarcinoma. Notably, the tumors were also richly distributed with a stromal component,
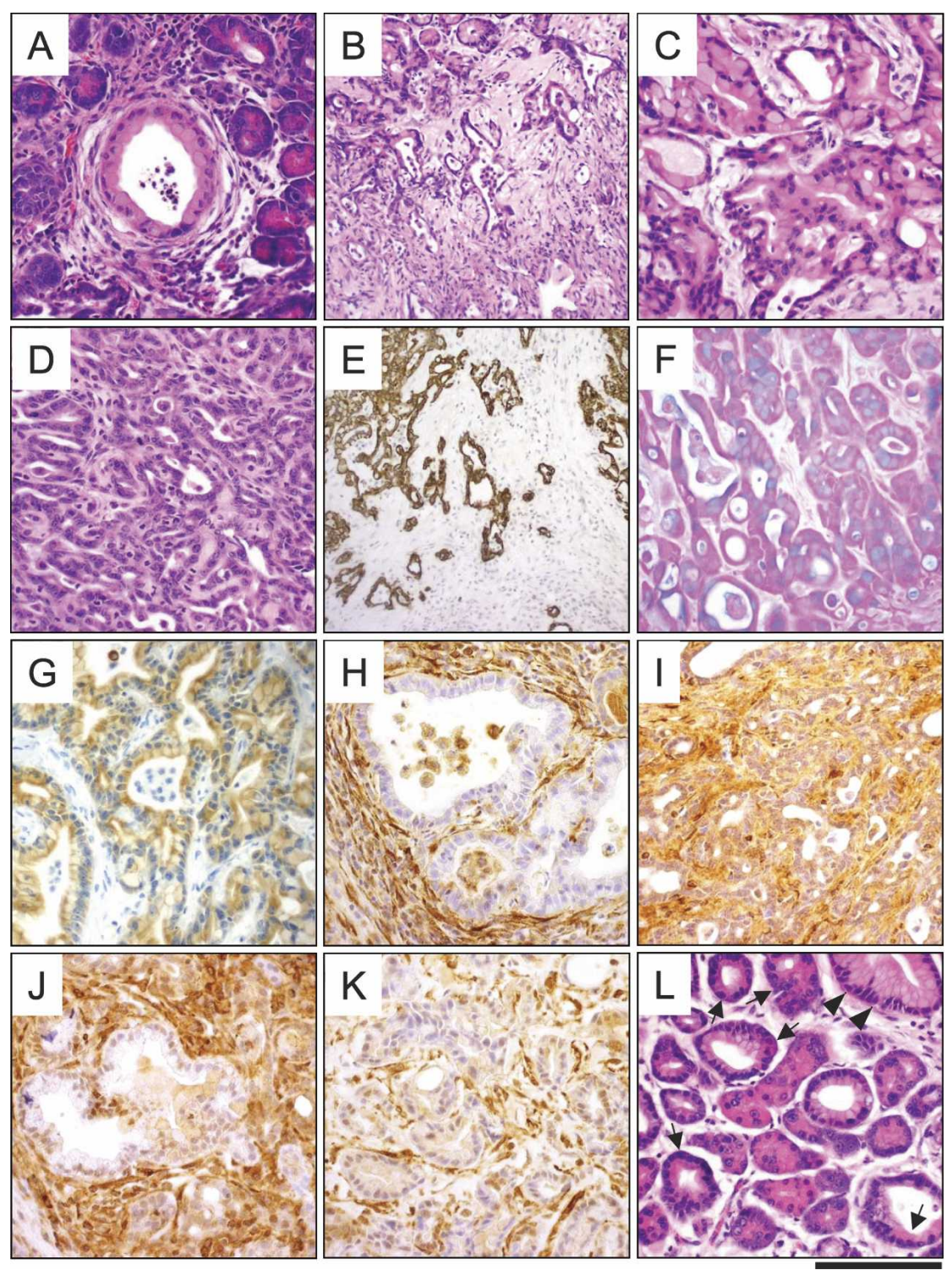

Figure 3. Histology of the Ptf $1 a^{\text {cre } /+} ; L S L$ Kras $^{G 12 D /+} ; T_{g f b r 2}{ }^{\text {flox } / \text { flox }}$ pancreatic tumors. Ptf1 $a^{\text {cre } /+} ; L S L-K_{r a s}{ }^{G 12 D /+}(A, H, J)$ and Ptf1 $a^{\text {cre } /+} ;$ LSL-Kras ${ }^{G 12 D /+} ;$ Tgfbr2 $^{\text {flox } / \text { flox }}(B-$ $G, I, K, L)$ pancreas (7-9 wk of age). $(A-D)$ $\mathrm{H} \& \mathrm{E}$ staining. (A) The Ptf $1 a^{\text {cre } /+} ; L S L-$ $\mathrm{Kras}^{\mathrm{G} 12 \mathrm{D} /+}$ mice showed mPanIN lesions surrounded by stromal capsule and still abundant normal pancreas areas. $(B)$ The Ptf1 $1 a^{\text {cre } /+} ;$ LSL-Kras ${ }^{\text {G12D/+ }}$; Tgfbr2 ${ }^{\text {flox/flox }}$ pancreas showed well-differentiated ductal adenocarcinoma, with a rich stromal component. Some areas still retained nuclear polarity and abundant cytoplasm $(C)$; however, others showed nuclear atypia and a high nuclear-cytoplasmic ratio $(D)$. $(E)$ Pan-cytokeratin staining revealed tumor epithelial cells invading into the stromal regions. Positive alcian blue $(F)$ and CK-19 staining $(G)$ confirmed the mucin-producing (blue), ductal phenotype of the tumor. Vimentin $(H, I)$ and smooth muscle actin $(J, K)$ staining was negative in the tumor epithelia, whereas prominent stromal infiltration (strong positive) was observed. $(L) \mathrm{H} \& \mathrm{E}$ staining of the Ptf $1 a^{\text {cre/+}}$; LSL-Kras ${ }^{G 12 D /+} ;$ Tgfbr2 flox/flox tumor also showed acinar-ductal metaplasia lesions. The arrows indicate acinar-ductal metaplasia (ductal lesions containing acinar granules). The arrowheads indicate an mPanIN-1B lesion. Bars: $B, E, 250 \mu \mathrm{m} ; A$, $C, D, F-L, 125 \mu \mathrm{m}$. 
showing positive for vimentin and smooth muscle actin staining (Fig. 3B,I,K), which was also found in the area surrounding mPanIN lesions in the $\mathrm{Ptf} 1 \mathrm{a}^{\mathrm{cre} /{ }^{+}} ; \mathrm{LSL}$ Kras $^{G 12 D /+}$ pancreas (Fig. $\left.3 \mathrm{H}, \mathrm{J}\right)$. This indicated that stromal expansion had started in the early tumorigenesis stages. Moreover, a distinct and important feature of this mouse model is that the Ptf $1 a^{\text {cre/+ }}$;LSL-Kras ${ }^{G 12 D /+}$; Tgfbr2 ${ }^{\text {flox/flox }}$ tumors did not show sarcomatoid architecture, which was seen in one-third of the $\operatorname{Kras}^{G 12 D}$ activation plus Ink4a/Arf knockout model (Aguirre et al. 2003). This feature is seen infrequently in human PDAC, providing another line of evidence that our mouse model is a close approximation of aggressive human PDAC. The penetrance of tumor appearance across all mice of the Ptf1a $\mathrm{Cre}^{\mathrm{H}}$; LSL-Kras ${ }^{\mathrm{G12D/+}}$;Tgfbr2 ${ }^{\text {flox/flox }}$ genotype examined was $100 \%$, and tumors were always accompanied by a whole panel of mPanINs and acinar-ductal metaplasia lesions (Fig. 3L).

The Ptf1 $a^{\text {cre } /+} ;$ LSL-Kras ${ }^{G 12 D /+} ;$ Tgfbr2 ${ }^{\text {flox } / \text { flox }}$ PDACs and Ptf1 $\mathrm{a}^{\mathrm{cre} /+}$;LSL-Kras ${ }^{\mathrm{G} 12 \mathrm{D} /+}$ mPanINs were strongly positive for EGFR, erbB2/Her2, and phospho-ERK (Fig. 4), while normal pancreatic ducts showed faint or negative staining (data not shown). This indicates that these signals were activated from the early stage of tumors, another feature closely paralleling the human disease (Hezel et al. 2006). E-cadherin was well maintained in the mPanIN lesions of Ptf1 $a^{\text {cre/+}} ;$ LSL-Kras ${ }^{G 12 D /+}$ mice, demonstrating typical cell-cell junctional staining, whereas the PDAC lesions of $\mathrm{Ptfla}^{\mathrm{cre} /+}{ }^{2} \mathrm{LSL}-\mathrm{Kras}^{\mathrm{G12D/+}}$;
Tgfbr2 ${ }^{\text {flox/flox }}$ mice revealed heterogeneity, with some areas completely lacking the junctional staining, while in many other areas it was still retained (Fig. 4). These results were consistent with another PDAC model (Hingorani et al. 2005) and suggested that the tumor was developing epithelial discontinuity and more invasive characteristics.

The pancreas epithelium-specific knockout of Tgfbr2 in the context of $\operatorname{Kras}^{G 12 D}$ expression revealed a dramatic enhancement of pancreatic tumor progression, and the tumor recapitulated human PDAC very closely.

Age progression of lesions in $\mathrm{Ptfl}^{\mathrm{cre} /{ }^{+}}$;LSL-Kras ${ }^{\mathrm{G} 12 \mathrm{D} /+}$; Tgfbr2 $2^{\text {flox/flox }}$ model

We next examined mice at earlier ages to assess the severity of development of these lesions over the postnatal period. At 3.5 wk of age, the Ptf1 $a^{\text {cre } /+}{ }_{;} L S L-K r a s{ }^{G 12 D /+}$; Tgfbr2 ${ }^{\text {flox/flox }}$ pancreas showed less frequent, but multifocal, isolated mPanINs and acinar-ductal metaplasia lesions surrounded by abundant normal pancreas area (Supplementary Fig. 1A-C), as was also observed in similar-age Ptf1a $\mathrm{Cre}^{\mathrm{cr}} ; \mathrm{LSL}-\mathrm{Kras}^{\mathrm{G12D/+}}$ mice. At this stage, mPanIN-type lesions could be clearly distinguished from those representing acinar-ductal metaplasia; the distribution of mPanIN-1A, mPanIN-1B, mPanIN-2, and mPanIN-3 was $22 \%, 39 \%, 28 \%$, and $11 \%$, respectively. No invasive cancer lesion was found at this stage. At 5 wk of age, the distribution had shifted toward $8.3 \%$,

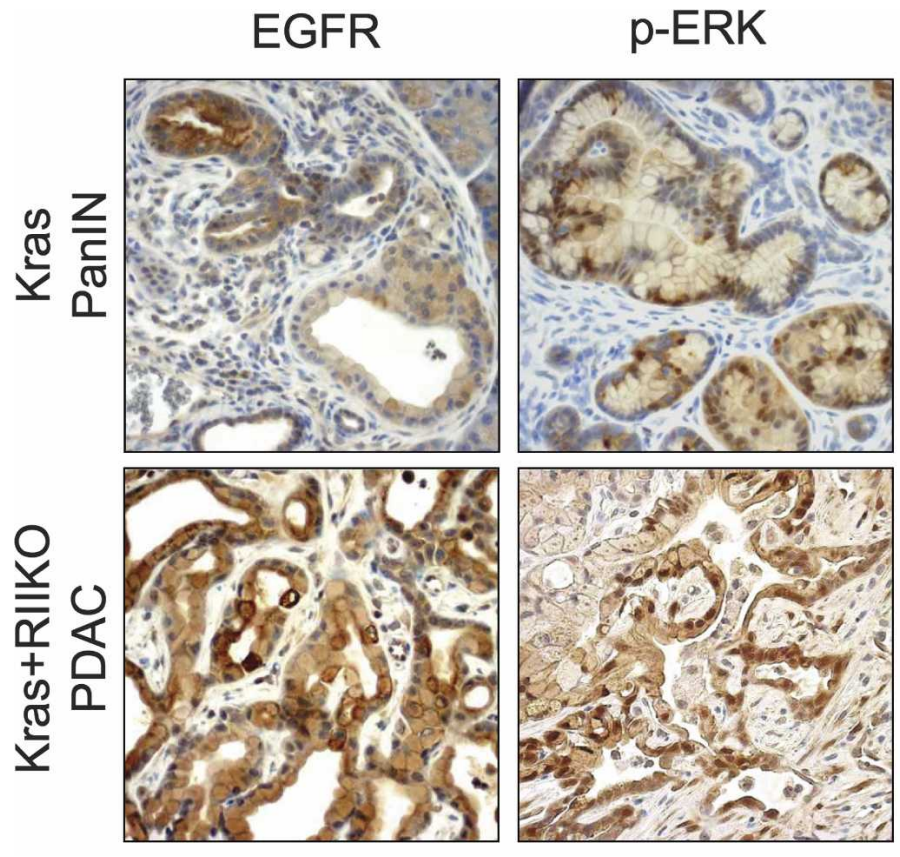

erbB2/Her2
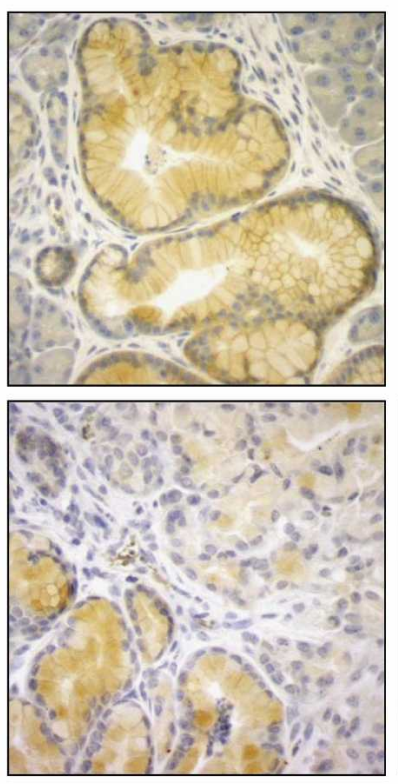

\section{E-cadherin}
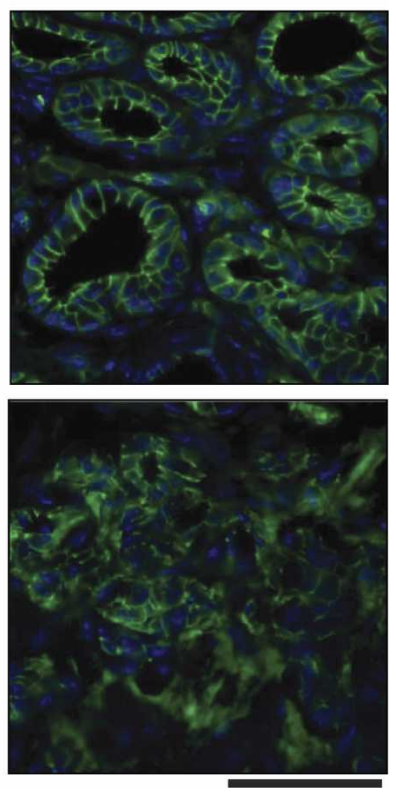

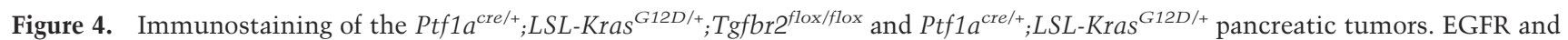

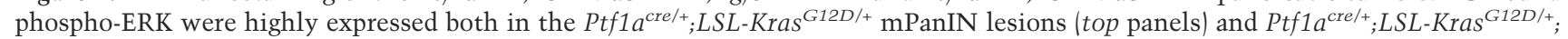
Tgfbr2 flox/flox PDAC lesions (bottom panels). erbB2/Her2 was also expressed in both lesions; however, more advanced stage lesions of the latter showed weaker or negative staining. E-cadherin immunofluorescence revealed a regular cell-junctional staining in the mPanIN lesions, whereas the PDAC lesions frequently showed nonjunctional, disorganized E-cadherin expression. (Green) E-Cad-

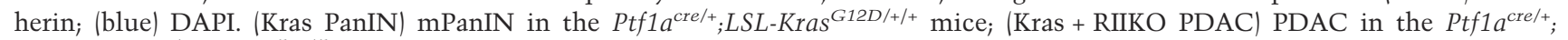
LSL-Kras ${ }^{G 12 D /+} ;$ Tgfbr2 ${ }^{\text {flox/flox }}$ mice. Bars, $125 \mu \mathrm{m}$. 
$20 \%, 17 \%$, and $29 \%$, respectively, in the same order, and invasive cancer lesions, which had invaded beyond the basement membrane, already accounted for $26 \%$ in the Ptf1 $a^{\text {cre } /+} ;$ LSL-Kras ${ }^{G 12 D /+} ;$ Tgfbr2 ${ }^{\text {flox/flox }}$ mice (Supplementary Fig. 1D,E). Mice with other genotypes had no PDAC lesions even at $7-10 \mathrm{wk}$ of age, when the whole pancreas in $\mathrm{Ptfl}^{\mathrm{cre} /+} ; \mathrm{LSL}-\mathrm{Kras}^{\mathrm{G12D/+}} ; \mathrm{Tg} f$ br ${ }^{\text {flox } / \text { flox }}$ mice had already become substituted by the tumor, resulting in loss of almost all normal acinar and islet tissue (Fig. 3B-D). We suggest that the order of appearance of the progressively more severe lesions is consistent with the hypothesis that there is a progression through a preceding stage of mPanIN lesion.

Invasive potential of the Ptfla $\mathrm{a}^{\mathrm{cre} /{ }_{i}} \mathrm{LSL}_{\mathrm{Kras}}{ }^{\mathrm{G} 12 \mathrm{D} /{ }^{+}}$; Tgfbr2 $2^{\text {flox/flox }} P D A C$

Lungs and livers of the tumor-bearing mice were subjected to histological analysis for metastasis (procedure in Supplemental Material). Although the tumors were very large, no distant metastasis was observed at 7-10 wk. The tumors showed minimal invasion into the duodenum, intrapancreatic lymph nodes, lymphatic channels, and/or nerve of peripheral pancreas, all of which are commonly found in human PDAC. Under this late-stage tumor burden, portal vein thrombosis was frequently detected $(8 / 25=32 \%)$. The main trunk of the portal vein was completely obstructed with thrombus frequently accompanied by fibroblast involvement, which resulted in multiple necrotic areas in the distal liver parenchyma (Supplementary Fig. 2). The mice also demonstrated paraplegia in three cases. This was likely because of circulation failure due to direct oppression of large vessels by the rapidly growing tumor.

Although most Ptf1 $a^{\text {cre } /+} ;$ LSL-Kras ${ }^{G 12 D /+} ;$ Tgfbr2 flox/flox mice had to be sacrificed at $7-10$ wk of age, three of this genotype survived up to 24-27 wk. All of them demonstrated PDAC with prominent desmoplasia and liver metastasis, and two showed lung metastasis, diaphragmatic and duodenal invasion, and peritoneal dissemination (Supplementary Fig. 2). These findings revealed that the Kras $^{G 12 D}$ expression plus Tgfbr2 knockout tumor had substantial invasive and metastatic potential, again recapitulating aggressive human PDAC. The age of $\sim 25 \mathrm{wk}$ was similar to the median survival of the $\operatorname{Kras}^{G 12 D}$ expression plus p53 inactivation model described previously (Hingorani et al. 2005). It is possible that the development of invasion and metastasis in all of the

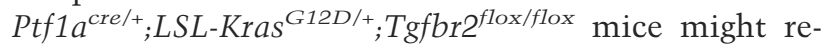
quire a period longer than most of them in this study could survive.

Molecular analysis of the Ptfla ${ }^{\mathrm{cre} /+}{ }_{\text {;LSL-Kras }}{ }^{\mathrm{G} 12 \mathrm{D} /{ }^{+}}$; Tgfbr2 $2^{\text {flox/flox }}$ tumor cells

Next, we established pancreatic cell lines from the $\mathrm{Ptf1}^{\mathrm{cre} /+} ;$ LSL-Kras ${ }^{\mathrm{G} 12 \mathrm{D} /+} ; \mathrm{Tgfbr}^{\text {flox/flox }}$ PDAC, as well as from the mPanIN-type lesions in the $P t f 1 a^{\text {cre } /{ }^{+}} ; L S L$ $\mathrm{Kras}^{G 12 D /+}$ pancreas. To address whether the mutant
Kras expression plus Tgfbr2 knockout is an independent tumorigenesis pathway from those of previous mouse models, the status of other tumor suppressor genes highly related to human PDAC, $p 16^{I N K 4 a}, p 53$, and Smad4 was examined using these cell lines. The coding sequences of those genes in several primary PDAC cell lines revealed no significant mutations, although one silent point mutation in Smad4 in one cell line was found (data not shown).

In Western blotting, Smad4 protein expression was detected in all cell lines examined (Fig. 5A). p53 was also expressed in most cell lines, and $\gamma$-irradiation induced p53 protein expression in most of the cell lines examined, which indicated normal p53 function in these cells (Fig. 5A,B). In contrast, the $\mathrm{p} 16^{\mathrm{INK} 4 \mathrm{a}}$ protein level varied among the cell lines, and p19 $9^{\mathrm{ARF}}$ protein, which is derived from the alternative reading frame of the DNA locus shared with $\mathrm{p} 16^{\mathrm{INK} 4 \mathrm{a}}$, was not detected in any cell lines including the Ptf1 $a^{\text {cre/+}} ;$ LSL-Kras ${ }^{\text {G12D/+ }}$ cells (Fig. $5 \mathrm{~A}$; data not shown). In RT-PCR analysis, p16 $6^{I N K 4 a}$ mRNA expression correlated well with that of protein, while $p 19^{A R F}$ mRNA expression was detected in most of the cell lines (Fig. 5C). The discrepancy of p19 ${ }^{\mathrm{ARF}} \mathrm{mRNA}$ and protein expression remains to be elucidated.

The type II TGF- $\beta$ receptor protein (T $\beta$ RII) expression
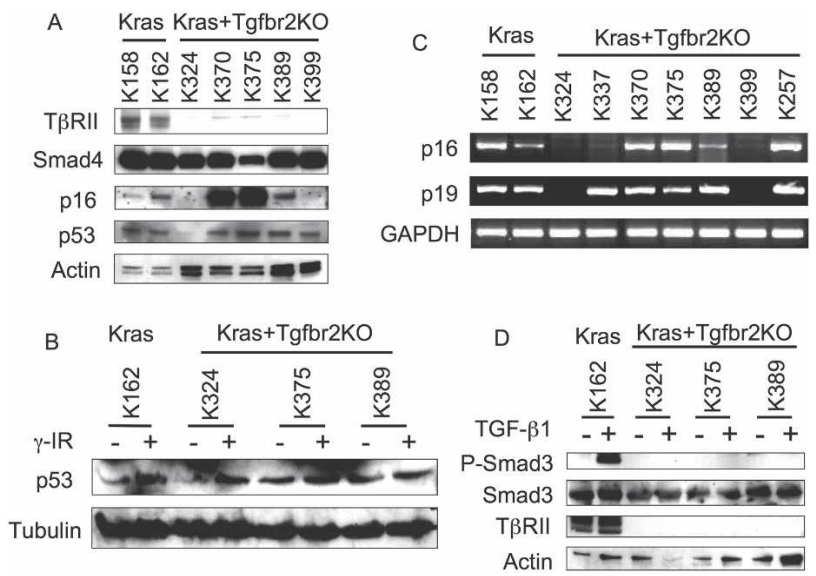

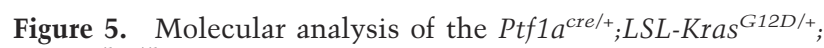
Tgfbr2 ${ }^{\text {flox/flox }}$ PDAC cell lines. $(A)$ Western blot analysis using total cell lysates of the established pancreatic cell lines from the $\mathrm{Ptfla}^{\text {cre/+}} ; \mathrm{LSL}-\mathrm{Kras}^{\mathrm{G12D/+}} ; \mathrm{Tg} f$ br $2^{\text {flox/flox }}$ PDAC (Kras + Tgfbr2KO cells) and $\mathrm{Ptf} \mathrm{a}^{\mathrm{cre} /+}, \mathrm{LSL}-\mathrm{Kras}^{\mathrm{G} 12 \mathrm{D} /+}$ pancreas (Kras cells) revealed intact Smad4, p53 protein expression in most of the cell lines and loss of T $\beta$ RII only in the Kras + Tgfbr2KO cell lines. p16 ${ }^{\mathrm{INK} 4 a}$ protein was variably expressed even in the Kras cell lines. (Actin) Loading control. (B) Analysis of p53 function by $\gamma$-irradiation. p53 protein was induced by $\gamma$-irradiation in all cell lines examined. (Tubulin) Loading control. (C) RT-PCR for $p 16^{I N K 4 a}$ and $p 19^{A R F}$ mRNA expression. $p 16^{I N K 4 a}$ mRNA level was variable in the cell lines, which was well correlated with the protein level. The $p 19^{A R F}$ mRNA level was relatively consistent with that of $p 16^{\text {INK4a }}$. (GAPDH) Loading control. (D) TGF- $\beta$-Smad signaling analysis. TGF- $\beta$-induced Smad 3 phosphorylation was found only in the Kras cells (T $\beta$ RII-intact), but was completely lost in all the Kras + Tgfbr2KO cells. (Actin) Loading control. 
and TGF- $\beta-$ Smad signaling were also analyzed. As expected by the Cre-mediated deletion, T $\beta$ RII expression was lost in all PDAC cell lines examined, and upon TGF$\beta 1$ stimulation, downstream Smad3 phosphorylation was abrogated in those PDAC cell lines, while it was clearly observed in the Tgfbr2-intact cells (Fig. 5A,D).

PI3K-Akt signaling was also examined in those cell lines. It was expected that both mPanIN and PDAC cells have Akt activation, since the PI3K-Akt pathway is one of those downstream from the active Kras signals. On the other hand, the TGF- $\beta$ signal activates the PI3K-Akt pathway, sometimes synergistically with the Kras signal (Janda et al. 2002). Our results showed Akt phosphorylation in both PDAC and mPanIN cells (Supplementary Fig. 3), which indicated that blockade of the TGF- $\beta$ signal does not inhibit PI3K-Akt signaling in the Ptf1 $\mathrm{a}^{\mathrm{cre} /{ }^{+}}$; LSL-Kras ${ }^{G 12 D /+}{ }^{\prime}$ Tgfbr2 flox/flox PDAC cells, and it is consistent with the cumulative data suggesting activation of this signal in human PDAC (for review, see Hezel et al. 2006). Cyclin D1, cyclin-dependent kinase 2 (CDK2), and CDK4 protein expression was also examined. Both the $\mathrm{mPanIN}$ and PDAC cell lines examined expressed abundant amounts of these proteins (Supplementary Fig. 3).

Taken together, the mutant Kras expression plus Tgfbr2 knockout was a sufficient combination for aggressive PDAC formation and progression through to large tumors with metastatic potential. Although some PDAC cells showed loss of both p16 ${ }^{\mathrm{INK} 4 \mathrm{a}}$ and T $\beta$ RII proteins, others retained intact $\mathrm{p} 16^{\mathrm{INK} 4 \mathrm{a}}$ protein expression. The precise relation of the status of Tgfbr2 and $p 16^{I N K 4 a}$, as well as $p 19^{A R F}$, remains to be investigated.

\section{Heterozygous loss of Tgfbr2 promotes PDAC progression along with mutant Kras expression}

Reduced TGF- $\beta$ signaling (haploinsufficiency at the Tgfbr2 locus) also seems to interact synergistically with expression of the activated Kras protein in terms of inducing tumors. Ptf1a ${ }^{\text {cre/+}} ; L S L-K_{r a s}{ }^{G 12 D /+} ;$ Tgfbr2 ${ }^{\text {flox/+ }}$ mice also have a reduced survival compared with control animals and a much longer latency than the Ptf1a ${ }^{\text {cre/+}}$; LSL-Kras ${ }^{G 12 D /+}{ }^{2}$ Tgfbr2 flox/flox (Fig. 2A). Different from the Ptf $1 a^{\text {cre } /+} ; L S L-K_{r a s}{ }^{G 12 D /+} ;$ Tgfbr2 $2^{\text {flox/flox }}$ mice, most of the Ptf1 $\mathrm{a}^{\mathrm{cre} /{ }^{+}} ;$LSL-Kras ${ }^{\mathrm{G12D/+}}$; Tgfbr2 ${ }^{\mathrm{flox} /+}$ mice did not show obvious symptoms (abdominal distension, weight loss, palpable hard tumor, ascites, or jaundice). When dissected at $\sim 200 \mathrm{~d}$ or later stage, firm, white-colored nodule(s) were frequently palpable in the pancreas head and/or body area; however, the tail area appeared normal.

The tumors in Ptf $1 \mathrm{a}^{\mathrm{cre} /+} ; \mathrm{LSL}-\mathrm{Kras}^{\mathrm{G12D/+}} ; \mathrm{Tg}$ fbr2 ${ }^{\text {flox/+ }}$ mice had a similar histology of well-differentiated ductal adenocarcinoma to that of the Ptf1 $a^{\text {cre/+}} ;$ LSL-Kras ${ }^{G 12 D /+}$; Tgfbr2 flox/flox tumors (Fig. 6A). Notably, the area of hard, white-colored mass in the pancreas head dominantly showed ductal adenocarcinoma histology, while the area of normally appearing pancreas tail dominantly showed mucin-rich glandular architecture corresponding to mPanIN-1B or mPanIN-2 (Fig. 6B). Normal pancreas structure had almost disappeared already.

These tumors frequently demonstrated gross metasta- sis to the liver and lung, direct invasion to the duodenum, and also peritoneal dissemination (Supplementary Table 2). The frequency of metastasis or invasion was much higher in the Ptf1a ${ }^{\text {cre } /+} ; L_{S L}-K_{r a s}{ }^{G 12 D /+}$; Tgfbr $2^{\text {flox/+ }}$ tumors dissected $(6 / 12=50 \%)$ than in the $\mathrm{Ptf1}^{\mathrm{cre} /{ }^{+}}$;LSL-Kras ${ }^{\mathrm{G12D/+}}$;Tgfbr2 ${ }^{\text {flox/flox }}$ tumors, although a certain number of the former cohort are still alive and must be examined later. It is suggested again that the latter cases could not survive long enough for metastasis or invasion due to the enormous tumor burden.

To determine whether the tumor had lost the wildtype allele of the Tgfbr2 gene through loss of heterzygosity $(\mathrm{LOH})$, we performed laser-capture microdissection to obtain tumor epithelial DNA for subsequent PCR analysis. Both the primary and metastatic tumors still retained the wild-type allele of the Tgfbr2 gene (Fig. 6C). The Ptf1a $a^{\text {cre } /+} ;$ LSL-Kras G12D/+ ${ }^{\text {Tgfbr2 }}{ }^{\text {flox/+ }}$ PDAC cell lines retained the wild-type Tgfbr2 allele and showed T $\beta$ RII protein expression and Smad3 phosphorylation upon TGF- $\beta$ stimulation, indicating that T $\beta$ RII protein function was also retained in those tumor cells (Supplementary Fig. 4), although some cells showed LOH and lost T $\beta$ RII expression, which might be secondary changes arising during cell culture. Smad4 protein was also expressed in all the cells examined (Supplementary Fig. 4). Taken together, it is still possible that point mutation of the Smad3 or 4 gene caused biallelic inactivation of the TGF- $\beta-$ Smad pathway; the data indicate that complete disruption of T $\beta$ RII signaling is not necessarily required for PDAC formation, and haploinsufficiency of TGF- $\beta$ signaling might be associated with PDAC progression, in the context of the mutant Kras expression.

Survival observation of $\mathrm{Ptf} 1 \mathrm{a}^{\mathrm{cre} /+}$;LSL-Kras ${ }^{\mathrm{G12D/+}}$ mice has still been ongoing. Among eight mice observed for $>200$ d, one mouse developed metastatic pancreatic tumor at $249 \mathrm{~d}$ of age. For precise statistical analysis between the Ptf1 $\mathrm{a}^{\mathrm{cre} /+} ; \mathrm{LSL}-\mathrm{Kras}^{\mathrm{G12D/+}} ; \mathrm{Tgfbr}^{\text {flox/+ }}$ and Ptf1 $a^{\text {cre/+}} ; L S L-K r a S^{G 12 D /+}$ mice, longer observation of the Ptf $1 a^{\mathrm{cre} /+}$; LSL-Kras ${ }^{G 12 D /+}$ group is required. However, there appears to be a clear difference in terms of tumor frequency, latency, and histology between these two lines. By the time the first invasive tumor developed in the Ptf1a ${ }^{\text {cre } /+}$;LSL-Kras ${ }^{G 12 D /+}$ line, seven invasive tu-

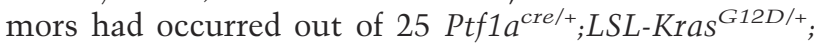
Tgfbr $2^{\text {flox } /+}$ mice $(7 / 25=28 \%)$. Thereafter, 18 of 25 mice developed invasive pancreatic tumor $(18 / 25=72 \%)$ with median survival $347 \mathrm{~d}$. According to the longer observations in the published studies, the median survival of the Kras-activated mice was described as $\sim 15$ mo (Hingorani et al. 2005) or 57 wk (Bardeesy et al. 2006), which are longer than that of the Ptf1 $\mathrm{a}^{\mathrm{cre} /{ }^{+}} ; \mathrm{LSL}-\mathrm{Kras}^{\mathrm{G} 12 \mathrm{D} /{ }^{+}}$; Tgfbr2 ${ }^{\text {flox/+ }}$ group in our study, although the latency might be affected by the difference of background strains.

Notably, three of eight Ptf1a $a^{\text {cre/+}} ;$ LSL-Kras ${ }^{G 12 D /+}$; Tgfbr2 ${ }^{\text {flox/+ }}$ tumors examined demonstrated a dominant sarcomatoid histology (50\% or more) as well as the ductal adenocarcinoma (Fig. 6D-F; Supplementary Table 2). The sarcomatoid feature appeared similar to those in the previously described models (Aguirre et al. 2003; Bar- 

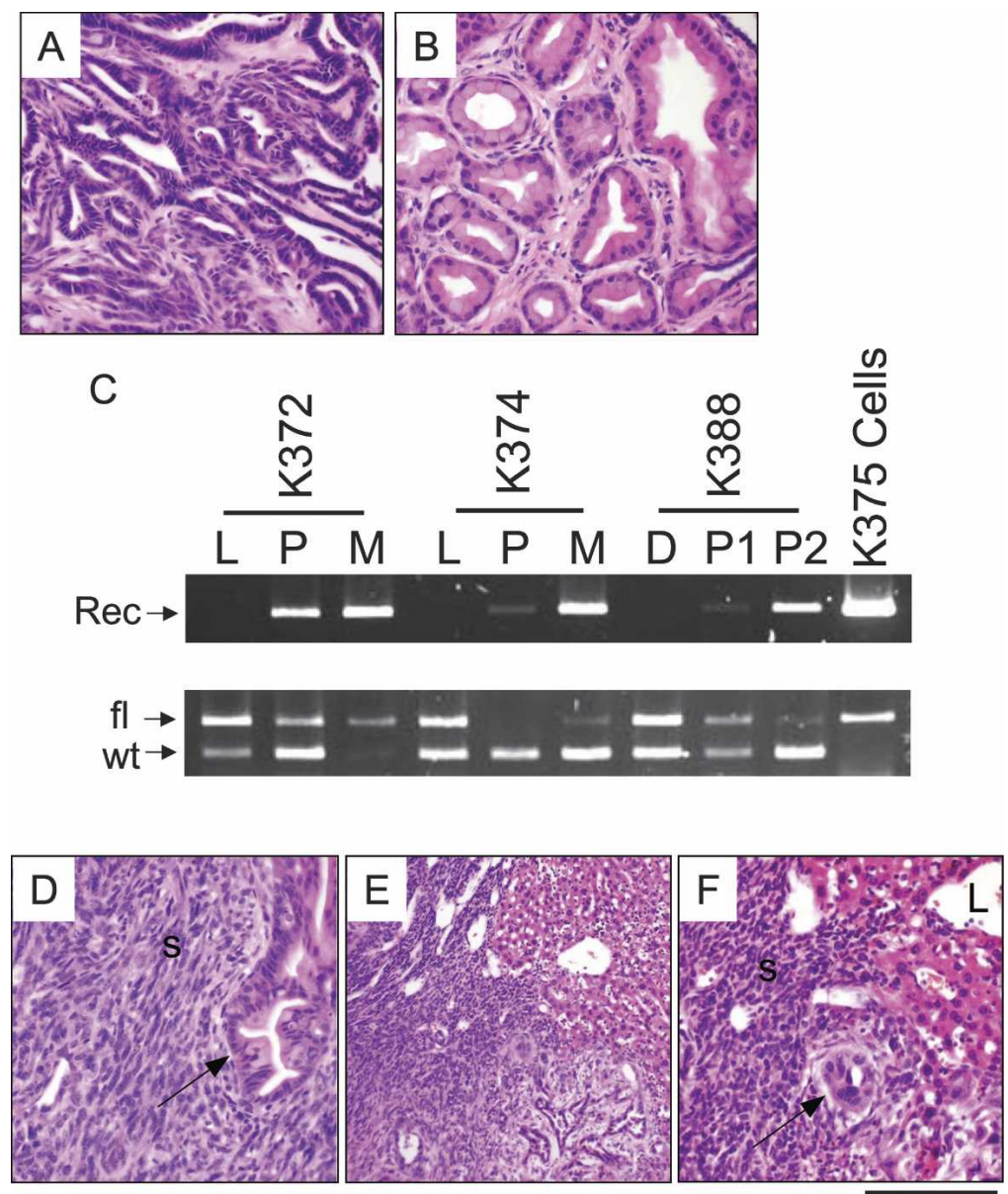

Figure 6. Haploinsufficiency of Tgfbr2 in the context of Kras $^{G 12 D}$ expression promoted PDAC progression. $(A, B) \mathrm{H} \&$ E staining of 32 -wk-old Ptf $1 a^{\text {cre } /+}$; LSL-Kras ${ }^{G 12 D /+} ;$ Tgfbr2 $2^{\text {flox } /+}$ mouse pancreas. $(A)$ Well-differentiated ductal adenocarcinoma in the pancreas head region. (B) mPanIN lesions were dominant in the pancreas tail region. $(C) \mathrm{LOH}$ analysis by PCR after laser-capture microdissection. DNA was extracted from the primary pancreas tumor epithelia, metastatic liver tumor epithelia, normal liver, or normal duodenum of the $\mathrm{Ptf} 1 \mathrm{a}^{\mathrm{cre} / \mathrm{H}} ; \mathrm{LSL}$ $\mathrm{Kras}^{\mathrm{G} 12 \mathrm{D} / \mathrm{+}} ; \mathrm{Tg} \mathrm{fbr} \mathrm{2lox}^{\mathrm{fl+}}$ mice, using laser-capture microdissection. Subsequent PCR showed that all primary pancreas tumor and one metastatic liver tumor epithelia clearly retained the wild-type $\mathrm{Tg} f b r 2$ allele (K372 P, K374 P and M, K388 P1 and P2), indicating a lack of LOH. (K372, K374, K388) Ptf1 $a^{\text {cre/+}}$; LSL-Kras ${ }^{G 12 D /+} ; \mathrm{Tgfbr}^{f l o x /+}$ mice; (K375 cells) a cell line of Ptf1 $a^{\text {cre } /+} ; L S L-K r a s{ }^{G 12 D /+} ; T g f b r 2^{\text {flox } / \text { flox }}$ mouse PDAC. (L) Normal liver; (D) normal duodenum; (P) primary pancreas tumor epithelia; (M) metastatic liver tumor epithelia; (P1) well-differentiated PDAC epithelia; (P2) poorly differentiated PDAC epithelia; (Rec) recombined; (fl) floxed; (wt) wild-type Tgfbr2 allele. $(D-F) \mathrm{H} \& \mathrm{E}$ staining of 50 wk-old Ptf1a $a^{\text {cre/+ }} ;$ LSL-Kras ${ }^{\text {G12D/+ }} ;$ Tgfbr2 ${ }^{\text {flox/+ }}$ mouse pancreas and liver. The tumor showed sarcomatoid histology (s) along with ductal adenocarcinoma lesions (arrow) (D), and both sarcomatoid (s) and ductal tumor (arrow) directly invaded into the liver parenchyma $(\mathrm{L})(E, F)$. Bars: $E, 250 \mu \mathrm{m} ; A-D, F, 125 \mu \mathrm{m}$. deesy et al. 2006). All the three tumors demonstrated aggressive metastasis and/or direct invasion, in which the spindle-shaped cells were spreading along with the ductal tumor cells (Fig. 6E,F). Again, these sarcomatoid tumors were not observed in the $P t f 1 a^{\mathrm{cre} /{ }^{+}} ; \mathrm{LSL}$ Kras $^{G 12 D /+} ; \mathrm{Tg} \mathrm{fbr}^{\text {flox } / \text { flox }}$ mice, indicating a distinct aspect of homozygous and heterozygous knockout of the Tgfbr2 gene. Moreover, the Pdx1-Cre;LSL-Kras G12D/+ and $P t f 1 a^{c r e /+} ; L S L-K r a s{ }^{G 12 D /+}$ pancreatic tumors, in all the cases published or that we observed, showed a dominant sarcomatoid or a significant poorly differentiated histology, specifically, 100\% sarcomatoid in one recent study (Hingorani et al. 2003; Bardeesy et al. 2006). Taken together, heterozygous loss of Tgfbr2, shown in the ${ }^{P t f 1 a^{\text {cre } /+}}{ }_{;}$LSL-Kras ${ }^{G 12 D /+}$; Tgfbr2 ${ }^{\text {flox } /+}$ mice, might promote PDAC progression differently from both, the homozygous knockout in the Ptf1a ${ }^{\text {cre } /+}$; LSL-Kras ${ }^{G 12 D /+}$; Tgfbr2 flox/flox mice and intact Tgfbr2 in the Ptf1a ${ }^{\text {cre/+}}$; LSL-Kras ${ }^{G 12 D /+}$ mice.

Connective tissue growth factor is strongly expressed in $\mathrm{Ptfla}^{\mathrm{cre} /{ }_{;}}$LSL-Kras ${ }^{\mathrm{G} 12 \mathrm{D} /{ }^{+}}{ }_{;}$Tgfbr $2^{\text {flox/flox }}$ PDAC stroma

What is the underlying mechanism in the rapid tumor progression in the Tgfbr2 knockout in the context of the mutant Kras expression? Strongly up- or down-regulated genes in the Ptf1 $\mathrm{are}^{\mathrm{cr} / \mathrm{H}} ; \mathrm{LSL}-\mathrm{Kras}^{\mathrm{G12D/+}} ; \mathrm{Tgfbr2} \mathrm{flox}^{\mathrm{flox}}$ PDAC compared with the Ptf1a ${ }^{\text {cre/+}} ;$ LSL-Kras ${ }^{G 12 D /+}$ mPanIN might provide important clues to understand the mechanism, and lead to the further identification of novel therapeutic targets for human PDAC. In this study we found that connective tissue growth factor (CTGF) was much more strongly expressed in the Ptf1 $a^{\text {cre/+ }} ; L S L$ Kras $^{G 12 D /+} ;$ Tgfbr2 $2^{\text {flox/flox }}$ PDAC tissues than in the ${\text { Ptf } 1 a^{\text {cre } /+} \text {; LSL-Kras }}^{\text {G12D/+ }}$ mPanIN lesions (Fig. 7A-D). Immunohistochemistry revealed that the mPanIN stroma showed negative staining in contrast to the mPanIN epithelia (Fig. 7A,B). In clear contrast to this, the PDAC demonstrated a strong CTGF staining mainly in the stromal area (Fig. 7C,D), which is consistent with the previous report that the main source of CTGF in normal tissue is the stroma (Grotendorst 1997). The expression was especially strong in the stroma adjacent to the tumor epithelia (Fig. 7C,D), which suggested an active nonautonomous tumor-stromal inductive interaction. Since CTGF is known as a downstream target of TGF- $\beta$ signaling (Grotendorst 1997) and PDAC tissue is also reported to express high levels of TGF- $\beta$ (Friess et al. 1993), we next examined active TGF- $\beta 1$ expression in the pancreas tissues by ELISA. It revealed higher TGF- $\beta 1$ expression in both the Ptf1a $a^{\text {cre/+ }} ;$ LSL-Kras ${ }^{G 12 D /+}$ mPanIN and the ${\text { Ptf } 1 a^{\text {cre } /+} ; \text { LSL-Kras }}^{\text {G12D/+}} ;$ Tgfbr2 ${ }^{\text {flox } / f l o x}$ PDAC tissues, 

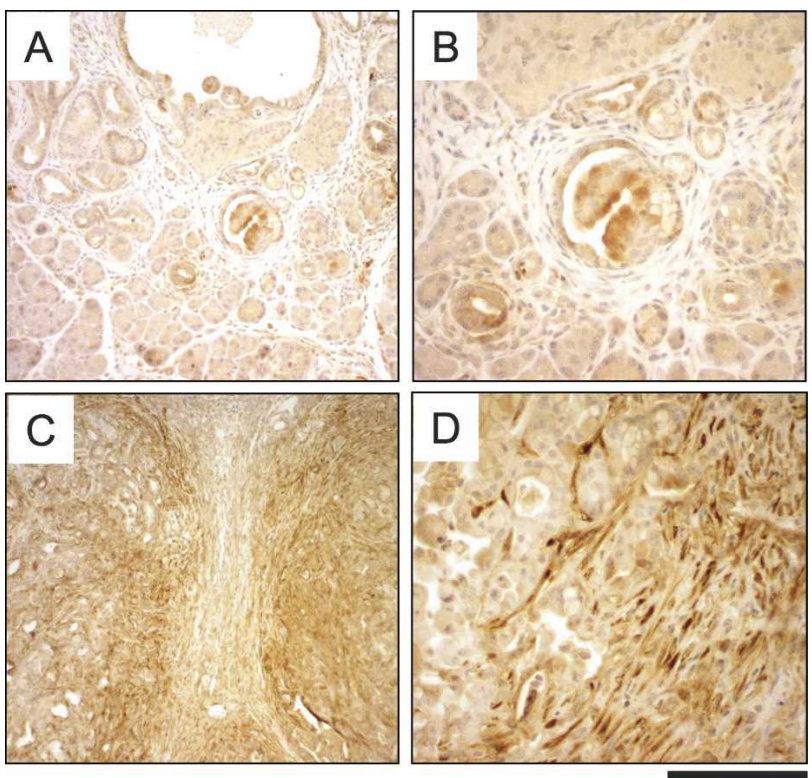

Figure 7. CTGF overexpression in the stroma of $P t f 1 a^{\text {cre } /+} ; L S L$ Kras $^{G 12 D /+} ;$ Tgfbr2 $^{\text {flox } / \text { flox }}$ PDAC. CTGF immunohistochemistry of 7-wk-old Ptf1a ${ }^{\text {cre } /{ }^{+}} ;$LSL-Kras ${ }^{G 12 D /+}(A, B)$ and Ptf1a ${ }^{\text {cre } /{ }^{+}} ; L S L-$ $\mathrm{Kras}^{\mathrm{G12D/+}} ; \mathrm{Tgfbr}^{\text {flox/flox }}(C, D)$ mouse pancreas. $(A)$ The Ptf1a ${ }^{\text {cre/+}}$; $L S L-K r a s^{G 12 D /+}$ pancreas stroma shows negative staining of CTGF. $(C, D)$ The Ptf1 $a^{\text {cre } /+} ;$ LSL-Kras ${ }^{G 12 D /+} ;$ Tgfbr2 ${ }^{\text {flox/flox }}$ PDAC stroma demonstrated strong expression of CTGF. Note that the stroma adjacent to the tumor epithelia especially exhibits high CTGF expression. Bars: $C, 500 \mu \mathrm{m} ; A, 250 \mu \mathrm{m} ; B, D, 125 \mu \mathrm{m}$.

in a clear contrast to the control LSL-Kras ${ }^{G 12 D /+}$; Tgfbr2 ${ }^{\text {flox/flox }}$ and the Ptf1 $a^{\text {cre } /+} ;$ Tgfbr2 $2^{\text {flox/flox }}$ pancreas (Supplementary Fig. 5). This suggested that high TGF- $\beta 1$ expression might have begun at the mPanIN stage and be sustained through PDAC progression.

\section{Discussion}

Pancreatic tumors arising in the Ptfla $\mathrm{a}^{\mathrm{cre} /+}$; LSL-Kras ${ }^{\mathrm{G} 12 \mathrm{D} /{ }^{+}}$; Tgfbr $2^{\text {flox/flox }}$ recapitulate human PDAC

The Ptf1a $a^{\text {cre } /+} ;$ LSL-Kras ${ }^{G 12 D /+} ;$ Tgfbr2 ${ }^{\text {flox/flox }}$ mice rapidly developed PDAC, which resembled human disease closely in both symptoms and histopathology. Recently, the consensus regarding the criteria for determining mouse PanIN and PDAC was published, which documented that mouse PDAC, which developed through mPanIN lesions originally from the duct cells, should be considered as a close parallel of human PDAC, with clear distinctions between $\mathrm{mPanIN}$ and acinar-ductal metaplasia (Hruban et al. 2006). The tumors in this study exhibited this tumorigenesis pathway as with the previous LSL-Kras ${ }^{G 12 D}$-based models (Aguirre et al. 2003; Hingorani et al. 2003, 2005). According to molecular analyses of the Ptf1 $a^{\text {cre } /+} ; L S L-K_{r a s}{ }^{G 12 D /+} ; \mathrm{Tgfbr}^{\text {flox/flox }}$ PDAC cell lines, the PDAC could develop without any alteration of other human PDAC-related tumor suppressor genes, p53, Smad4, and $p 16^{I N K 4 a}$, which indicated that the combination of Tgfbr2 knockout and active Kras expression was an independent tumorigenesis pathway of mouse PDAC from those of the previous mouse models. On the other hand, some of the PDAC cell lines showed both $p 16^{I N K 4 a}$ and Tgfbr2 inactivation. It also suggested that there might be a certain underlying association in the $\mathrm{p} 16^{\mathrm{INK} 4 \mathrm{a}}$ and TGF- $\beta$ signaling pathways, which is similarly found as $p 16^{I N K 4 a}$ and Smad4 inactivation in human PDAC (Rozenblum et al. 1997). Taken together, the Ptf1a ${ }^{\text {cre } /+} ; L S L-K_{r a s}{ }^{G 12 D /+} ; T_{g f b r} 2^{\text {flox } / f l o x}$ mouse represents a novel mouse model of human PDAC.

The Ptf1 $1 \mathrm{a}^{\mathrm{cre} /+} ;$ LSL-Kras ${ }^{\mathrm{G12D/+}} ; \mathrm{Tg}$ fbr2 ${ }^{\text {flox/flox }}$ tumors uniformly demonstrated well-differentiated ductal adenocarcinoma, but not sarcomatoid tumor, in contrast to the Pdx1-Cre;LSL-Kras ${ }^{G 12 D /+}$;Ink4a/Arflox/lox model (Aguirre et al. 2003), one-third of which showed sarcomatoid tumor, an infrequent type in human PDAC. Both models similarly showed a very short survival, which was much shorter than that of the Pdx1-Cre;LSL$\mathrm{Kras}^{\mathrm{G12D/+}}$;LSL-Trp53 ${ }^{R 172 H /+}$ model (median survival: 8.4 wk vs. $5 \mathrm{~mol}$ (Hingorani et al. 2005). The Ptf1 $a^{\text {cre/+}}$; LSL-Kras ${ }^{G 12 D /+} ;$ Tgfbr2 flox/flox tumors also showed distant metastasis, direct invasion, and peritoneal dissemination, only when the mice survived until a similar age to those of the Pdx1-Cre;LSL-Kras ${ }^{G 12 D /{ }^{+}} ; L S L-$ $\operatorname{Trp} 53^{R 172 H /+}$ model, which showed highly metastatic tumors. In the recent study (Bardeesy et al. 2006), $P d x 1$ Cre;LSL-Kras ${ }^{G 12 D /+}$; p53 $^{\text {lox/lox }}$, Pdx1-Cre;LSL-Kras ${ }^{\text {G12D/+ }}$; p53 ${ }^{\text {lox/+ }}$, and Pdx1-Cre;LSL-Kras ${ }^{\text {G12D/+ }} ;$ p5 $^{\text {lox/+ }} ;$ p16 $6^{+/-}$ show a similar phenotype to human PDAC. Although occasional undifferentiated carcinoma was seen, these three show basically differentiated PDAC with distant metastasis, unless they die early due to the enormous tumor burden. This relationship of metastasis frequency and survival period was also seen in our model. Thus, in terms of short survival and differentiated histology, the $\mathrm{Ptf1}^{\mathrm{cre} /{ }^{+}}$; LSL-Kras ${ }^{\mathrm{G12D/+}} ; \mathrm{Tg}$ fbr2 ${ }^{\text {flox/flox }}$ tumors might be one of the closest mouse models of human PDAC, suggesting the impact of blockade of TGF- $\beta$ signaling.

These previously described LSL-Kras ${ }^{G 12 D}$-based models used the $P d x 1$ promoter to drive Cre recombinase. In this study, the Ptf1 $a^{\text {cre/+ }}$ system showed pancreas-specific, homogeneous Cre recombination, not only in acinar cells but also ductal cells (Fig. 1B,C). In contrast, the $P d x 1$-Cre system shows more heterogeneity in Cre expression (Hingorani et al. 2003). Moreover, the Ptf1a $a^{\text {cre/+ }}$ system was more specific to pancreas than the Pdx1-Cre model. The Pdx1-Cre system developed extra-pancreas tumors (Aguirre et al. 2003; Hingorani et al. 2005), which might affect several aspects of the disease conditions. In contrast, the Ptf $1 a^{c r e /+}$ system did not show any extrapancreatic phenotype in this study, even in the cerebellum (data not shown), where Ptfla is also highly expressed and important for normal organ development (Hoshino et al. 2005). This suggests that there might be a certain advantageous circumstance in the pancreas, and not in the cerebellum, for tissue-specific contextdependent response of cells in the Ptf1 $1 a^{\text {cre/+ }}$ system; that is, the impact of $\mathrm{Kras}^{G 12 D}$ activation and blockade of TGF- $\beta$ signaling becomes prominent only in the pancreas, not in the cerebellum. This may be because of a 
different proliferative mechanism, or prolonged plasticity and proliferative potential in the pancreas compared with the cerebellum, or stromal interaction that is deeper in pancreas than in the brain region. Accordingly, the Ptf $1 a^{\text {cre/+}} ;$ LSL-Kras ${ }^{G 12 D /+} ; \mathrm{Tg} f b r 2^{\text {flox } / f l o x}$ mice may have several advantages compared with other existing mouse models.

\section{Underlying mechanism of PDAC progression induced by Tgfbr2 knockout in the context of active Kras expression}

As described above, the blockade of TGF- $\beta$ signaling has a great impact on Kras-induced PDAC progression. What is the mechanism underlying the dramatic tumor progression in the Tgfbr2 knockout in the context of active Kras expression? Since TGF- $\beta$ is a growth inhibitor of epithelial cells, it is possible that deprivation of this signal by knockout of Tgfbr2 might confer privileges to those cells for autonomous proliferation, resulting in rapid tumor formation. However, Tgfbr2 knockout alone did not cause any abnormalities up to $1.5 \mathrm{yr}$ of age. It was suggested that Kras activation might be required first as a tumor-initiating event, and then the inactivation of either tumor suppressor gene $p 16^{I N K 4 a}, p 53, T g f b r 2$, or Smad4 should occur for promoting tumor progression, which seems similar to the clinical findings for human PDAC. It seems also the same in other organs, that Tgfbr2 knockout alone does not initiate tumor formation, unless certain oncogene activation or chemical initiation exists (Forrester et al. 2005; Lu et al. 2006). To clarify the direct effect of TGF- $\beta$ signal blockade on the mutant Kras-initiated PDAC progression, Tgfbr2 knockdown in the $\mathrm{Ptfla}^{\mathrm{cre} /+}{ }_{;}$LSL-Kras ${ }^{\mathrm{G} 12 \mathrm{D} /+}$ cells using siRNA might provide a better understanding of this tumorigenic process.

TGF- $\beta$ signaling appears to be important especially in epithelial-stromal interaction (Bierie and Moses 2006). The vast stroma uniformly found in the $P t f 1 a^{\text {cre/t }}$; LSL$\operatorname{Kras}^{G 12 D /+} ; T_{g f b r}{ }^{\text {flox } / f l o x}$ tumors also suggested there might be active interaction between the tumor and stroma. In this study, we showed strong CTGF expression in the PDAC stroma, especially the area adjacent to the tumor epithelium, which might reflect an active tumor-stromal interaction. Although CTGF is known as one of the target genes downstream from the TGF- $\beta$ signal, high levels of TGF- $\beta 1$ found in both the PDAC and mPanIN might not be able to explain the clear contrast of CTGF expression between the two, high in PDAC and low in mPanIN stroma. There might be another mechanism in the strong CTGF expression in the PDAC stroma. It was recently reported that CTGF promoted growth and invasion of pancreatic cancer cell lines in vitro, and its specific antibody attenuated orthotopic pancreatic tumor progression in vivo (Aikawa et al. 2006). Therefore, testing the activity of CTGF-blocking antibodies in this new mouse PDAC model might be effective. A positive result in this respect would lend strong support for developing a novel approach for target therapy of PDAC; that is, to target molecules expressed not just in the tumor epithelium itself but in the stromal cells that provide nonautonomous maintenance and progression signals, as was proposed in a recent study (Lu et al. 2006). In this regard, other stromal components (matrix metalloproteinases, tissue inhibitors of metalloproteinases, etc.) might be further investigated.

The level of TGF- $\beta$ signal might be a significant determinant of pancreatic tumor formation and histology

The Ptf $1 a^{\text {cre } /+} ;$ LSL-Kras ${ }^{G 12 D /+} ;$ Tgfbr $2^{\text {flox } /+}$ mice also developed PDAC while retaining one wild-type Tgfbr2 allele, which indicated that complete knockout of Tgfbr2 is not always required, but that decreased TGF- $\beta$ signaling can promote quite severe PDAC progression. The tumors progressed much more slowly than the complete Tgfbr2 knockout, presenting with less symptoms, although resulting in a similar final histology and a more frequent metastatic spread. In terms of decreased level of signaling, reduced Tgfbr2 expression by epigenetic silencing is already reported in human lung and prostate cancer (Zhang et al. 2004; Zhao et al. 2005), although there are controversial studies in pancreatic cancer that showed decreased or increased Tgfbr2 mRNA expression in the tumor tissues (Wagner et al. 1999; Venkatasubbarao et al. 2000). We found a gradation of tumors in the Ptf1 $a^{\text {cre/+}} ; \mathrm{LSL}-\mathrm{Kras}^{\mathrm{G12D/+}} ; \mathrm{Tg}_{\mathrm{fbr}} \mathrm{flox} /+^{\text {flo }}$ mice, in which the PDAC lesions were frequently located in the pancreas head and body with low-grade mPanIN lesions in the tail area. The same pattern likely exists in earlier-age $\mathrm{Ptf1}^{\text {cre/+}} ; \mathrm{LSL}-\mathrm{Kras}^{\mathrm{G} 12 \mathrm{D} /+} ; \mathrm{Tg} f \mathrm{fbr} 2^{\text {flox/flox }}$ mice, according to the 5-wk-old mice study, in which there was a minor invading tumor area in the pancreas head, contained within an abundant normal pancreatic tissue. What determines the difference in propensity to PDAC progression between the pancreas head and tail, which is also seen in human PDAC, remains to be investigated. It is known that the body and tail of the pancreas are derived from the dorsal pancreatic bud, while the head of the pancreas is mostly derived from the ventral pancreatic bud (Werlin 2004). This suggests that the difference of phenotypic response to carcinogenic genetic changes between the pancreas head and tail might be connected to genetic difference of their initial developmental anlagen, the ventral and dorsal buds.

In this study, three among eight $P t f 1 a^{\text {cre } /+} ; L S L$ Kras $^{G 12 D /+} ; \mathrm{Tgfbr}^{\text {flox } /+}$ mice examined demonstrated sarcomatoid tumor along with well-differentiated PDAC. In contrast, all 25 Ptf $1 a^{\text {cre/t}} ;$ LSL-Kras ${ }^{G 12 D /+}$;

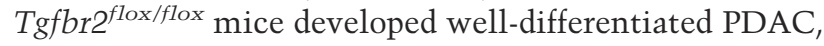
and none of them showed sarcomatoid histology. Since the sarcomatoid tumors always accompanied differentiated PDAC, it was likely derived through the mechanism of epithelial-mesenchymal transdifferentiation (EMT). Because the TGF- $\beta$ signal is known to induce EMT as one of its major functions (Zavadil and Bottinger $2005)$, the amount of intact TGF- $\beta$ signaling might be one of the important determinants of pancreatic tumor histology; that is, the more the TGF- $\beta$ signal is intact, 
the more sarcomatoid tumor is obtained through EMT. Among the previously described PDAC models, the tumors that had both $p 16^{I N K 4 a}$ alleles inactivated demonstrated a higher frequency of sarcomatoid histology (Aguirre et al. 2003; Bardeesy et al. 2006), all of which seemed to have intact TGF- $\beta$ signaling. The relation of $p 16^{I N K 4 a}$ inactivation and EMT remains to be investigated. As described above, some areas of the Ptf1 $a^{\text {cre/+}}$; LSL-Kras ${ }^{G 12 D /+} ; \mathrm{Tg} f b r 2^{\text {flox/flox }}$ tumor, however, showed E-cadherin mislocalization (Fig. 4), which might be associated with EMT. The Ptf1 $\mathrm{a}^{\mathrm{cre} / \mathrm{+}}$; LSL-Kras ${ }^{\mathrm{G12D/+}}$; Tgfbr2 flox/flox PDAC cells have more E-cadherin dysfunction than the mPanIN cells, but might still retain more functional E-cadherin than other PDAC cells that showed a sarcomatoid pattern.

It has been reported that either the wild-type $p 16^{I N K 4 a}$, Ink4a/Arf, or p53 allele was lost by LOH or inactivated by promoter methylation in the tumors of compound heterozygous genotype mice in the context of the $P d \times 1$ Cre;LSL-Kras ${ }^{G 12 D /+}$ background (Bardeesy et al. 2006). Therefore, haploinsufficiency of TGF- $\beta$ signal might be a unique mechanism in PDAC progression.

\section{Different phenotypes of Tgfbr2 knockout and Smad4} knockout in the context of active Kras expression

This study has demonstrated that blockade of TGF- $\beta$ signaling might have significance in PDAC formation; however, mutation or deletion of the Tgfbr2 gene is found in $<5 \%$ of human pancreatic cancer, among them especially in medullary carcinoma, a rare variant of pancreatic cancer (Goggins et al. 1998), although epigenetic silencing of Tgfbr2 may occur more frequently in human PDAC.

In contrast, the incidence of Smad4 mutation or deletion is $55 \%$. Therefore, one might suggest that the Smad4 knockout (plus Kras ${ }^{G 12 D}$ expression) could provide a model more closely recapitulating human PDAC than that of the Tgfbr2 knockout plus Kras ${ }^{G 12 D}$ expression model (Kras + Tgfbr2KO) presented here. Pancreasspecific Smad4 knockout mice (Pdx1-Cre;Smad4lox/lox and Ptf1a $a^{\text {cre/+}}$;Smad4 ${ }^{\text {lox/lox })}$ also showed normal pancreas development similar to the Tgfbr2 knockout $(\mathbf{N}$. Bardeesy and R.A. DePinho, pers. comm.). In contrast, pancreas-specific $\operatorname{Kras}^{G 12 D}$ expression plus Smad4 knockout (Kras + Smad4KO) mice (Pdx1-Cre;LSL-

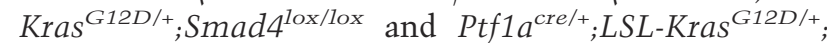

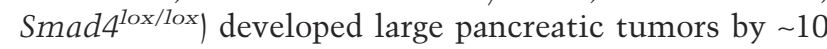
wk with $100 \%$ penetrance. However, the tumor phenotype of Kras + Smad4KO differed from the Kras + Tgfbr2KO in that they were less aggressive. The Kras + Smad4KO mice developed intraductal papillary mucinous neoplasm (IPMN) that progressed to frank PDAC at low penetrance (N. Bardeesy and R.A. DePinho, pers. comm.); on the other hand, Smad4 deficiency cooperated with $\operatorname{Kras}^{G 12 D}$ and Ink4a/Arf heterozygosity to promote rapid development of PDAC. The more aggressive character of the tumor in the Kras + Tgfbr2KO compared with the Kras + Smad4KO (with intact Ink4a/Arf) might be explained by the idea that the knockout of
Tgfbr2 abrogates all signaling downstream from the TGF- $\beta$ receptors, having more impact than preventing only Smad4-dependent signal transduction. Since Smad4 is also a central signal mediator downstream from bone morphogenetic protein (BMP) and activin (Miyazono et al. 2000), one may suggest that blockade of BMP or activin signaling might be contributing to human PDAC progression. However, our study demonstrates that blockade of TGF- $\beta$ signaling (with $\operatorname{Kras}^{G 12 D}$ expression) is sufficient to promote aggressive PDAC progression.

In conclusion, the Ptf $1 a^{\text {cre } /+} ; L_{S L}-K_{r a s}{ }^{G 12 D /+}$; Tgfbr $2^{\text {flox/flox }}$ mice present a promising PDAC model with a very close approximation, by several key criteria, to the severe aggressive form of the human disease. Further intensive investigation of this model will provide a better understanding of the lethal PDAC and assist in developing new therapies.

\section{Materials and methods}

Generating mouse lines

Tgfbr2 ${ }^{\text {flox/flox }}$ mice (C57BL/6) (Chytil et al. 2002) were mated with Ptf1 $a^{\text {cre/+ }}$ mice (C57BL/6/DBA/2) (Kawaguchi et al. 2002) to generate Ptf1 $a^{\text {cre/+ }}$; Tgfbr2 flox/flox mice (C57BL/6/DBA/2). Then, the Ptf1acre/+,$T g f b r 2^{\text {flox } / f l o x}$, and LSL-Kras ${ }^{G 12 D /+}$ mice (129/SvJae/C57BL/6) (Jackson et al. 2001) were interbred to ob-

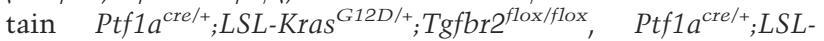
$\mathrm{Kras}^{\mathrm{G12D/+}} ; \mathrm{Tg} f \mathrm{fr} 2^{\text {flox } /+}$, and littermate control mice on a mixed C57BL/6/DBA/2/129/SvJae background. Some mice were also bred with Rosa26 lacZ reporter mice (C57BL/6) (Soriano 1999) for the purpose of tracing Cre-recombinase expression driven by the Ptf1a promoter. All mice were housed in the Animal Care Facility at Vanderbilt University following the Association for the Assessment and Accreditation of Laboratory Animal Care guidelines.

Mouse genotyping and recombined allele detection

Genotyping of Ptf1 $a^{\text {cre }}, L S L-K r a s^{G 12 D}$, floxed Tgfbr2 alleles, and $L S L-K_{r a s}{ }^{G 12 D}$ and $T g f b r 2$ recombined allele detection were performed by using oligonucleotide primers as described previously (Jackson et al. 2001; Chytil et al. 2002; Kawaguchi et al. 2002; Hingorani et al. 2003; Cheng et al. 2005). Recombined alleles were detected by using genomic DNA extracted from paraffinembedded pancreas and liver tissue.

\section{Histopathology}

Mouse tissue was harvested and processed as described before (Forrester et al. 2005). Immunohistochemistry for vimentin and smooth muscle actin was performed by the Vanderbilt Histology Core Facility. Other antibodies and procedures used are in the Supplemental Material.

\section{Establishing primary pancreatic cell lines}

Mouse pancreas cells were separated and cultured in Vitrogen/ Fibronectin-coated dishes in the RPMI media supplemented with $20 \%$ fetal bovine serum and antibiotics to obtain pure pancreas epithelial cell populations (Aguirre et al. 2003; Forrester et al. 2005). After the cells reached pure population, all experiments were performed within eight passages, to avoid 
possible gross genomic changes during long-term in vitro culture.

\section{Molecular analysis of the primary pancreatic cell lines}

RNA and protein of the primary mouse pancreatic cell lines were extracted for subsequent RT-PCR, sequencing, and Western blotting. Specific reagents and procedures are in the Supplemental Material.

\section{Laser-capture microdissection}

Epithelial tissue of primary pancreatic tumor, metastatic liver tumor, normal liver, and normal duodenum of the Ptf1 $1 a^{\text {cre/+}}$; $L S L-\mathrm{Kras}^{\mathrm{G12D} /+} ; \mathrm{Tg} f b r 2^{\text {flox/+ }}$ mice was microdissected by laser, and DNA was extracted as described before (Cheng et al. 2005). Subsequently, PCR was performed for detection of wild-type, floxed, and recombined alleles of Tgfbr2.

Other experimental procedures are described in the Supplemental Material.

\section{Acknowledgments}

We thank Phillippe Soriano for providing the ROSA26r mice, David A. Tuveson and Tyler Jacks for providing the LSL$\mathrm{Kras}^{\mathrm{G12D} /+}$ mice, and Nabeel Bardeesy and Ronald A. DePinho for useful technical information and helpful discussions. H.I. is supported by the Uehara Memorial Foundation. This work is supported by grants CA 085492 and CA 102162 to H.L.M. and the T.J. Martell foundation.

\section{References}

Aguirre, A.J., Bardeesy, N., Sinha, M., Lopez, L., Tuveson, D.A., Horner, J., Redston, M.S., and DePinho, R.A. 2003. Activated Kras and Ink4a/Arf deficiency cooperate to produce metastatic pancreatic ductal adenocarcinoma. Genes \& Dev. 17: 3112-3126.

Aikawa, T., Gunn, J., Spong, S.M., Klaus, S.J., and Korc, M. 2006. Connective tissue growth factor-specific antibody attenuates tumor growth, metastasis, and angiogenesis in an orthotopic mouse model of pancreatic cancer. Mol. Cancer Ther. 5: 1108-1116.

Bardeesy, N., Aguirre, A.J., Chu, G.C., Cheng, K.H., Lopez, L.V., Hezel, A.F., Feng, B., Brennan, C., Weissleder, R., Mahmood, U., et al. 2006. Both p16(Ink4a) and the p19(Arf)-p53 pathway constrain progression of pancreatic adenocarcinoma in the mouse. Proc. Natl. Acad. Sci. 103: 5947-5952.

Bierie, B. and Moses, H.L. 2006. TGF- $\beta$ and cancer. Cytokine Growth Factor Rev. 17: 29-40.

Bottinger, E.P., Jakubczak, J.L., Roberts, I.S., Mumy, M., Hemmati, P., Bagnall, K., Merlino, G., and Wakefield, L.M. 1997. Expression of a dominant-negative mutant TGF- $\beta$ type II receptor in transgenic mice reveals essential roles for TGF- $\beta$ in regulation of growth and differentiation in the exocrine pancreas. EMBO J. 16: 2621-2633.

Cheng, N., Bhowmick, N.A., Chytil, A., Gorksa, A.E., Brown, K.A., Muraoka, R., Arteaga, C.L., Neilson, E.G., Hayward, S.W., and Moses, H.L. 2005. Loss of TGF- $\beta$ type II receptor in fibroblasts promotes mammary carcinoma growth and invasion through upregulation of TGF- $\alpha-$, MSP- and HGF-mediated signaling networks. Oncogene 24: 5053-5068.

Chytil, A., Magnuson, M.A., Wright, C.V., and Moses, H.L. 2002. Conditional inactivation of the TGF- $\beta$ type II receptor using Cre:Lox. Genesis 32: 73-75.

Derynck, R., Akhurst, R.J., and Balmain, A. 2001. TGF- $\beta$ sig- naling in tumor suppression and cancer progression. Nat. Genet. 29: 117-129.

Forrester, E., Chytil, A., Bierie, B., Aakre, M., Gorska, A.E., Sharif-Afshar, A.R., Muller, W.J., and Moses, H.L. 2005. Effect of conditional knockout of the type II TGF- $\beta$ receptor gene in mammary epithelia on mammary gland development and polyomavirus middle $\mathrm{T}$ antigen induced tumor formation and metastasis. Cancer Res. 65: 2296-2302.

Friess, H., Yamanaka, Y., Buchler, M., Ebert, M., Beger, H.G., Gold, L.I., and Korc, M. 1993. Enhanced expression of transforming growth factor $\beta$ isoforms in pancreatic cancer correlates with decreased survival. Gastroenterology 105: 18461856.

Goggins, M., Shekher, M., Turnacioglu, K., Yeo, C.J., Hruban, R.H., and Kern, S.E. 1998. Genetic alterations of the transforming growth factor $\beta$ receptor genes in pancreatic and biliary adenocarcinomas. Cancer Res. 58: 5329-5332.

Grotendorst, G.R. 1997. Connective tissue growth factor: A mediator of TGF- $\beta$ action on fibroblasts. Cytokine Growth Factor Rev. 8: 171-179.

Hahn, S.A., Schutte, M., Hoque, A.T., Moskaluk, C.A., da Costa, L.T., Rozenblum, E., Weinstein, C.L., Fischer, A., Yeo, C.J., Hruban, R.H., et al. 1996. DPC4, a candidate tumor suppressor gene at human chromosome 18q21.1. Science 271: 350-353.

Hezel, A.F., Kimmelman, A.C., Stanger, B.Z., Bardeesy, N., and Depinho, R.A. 2006. Genetics and biology of pancreatic ductal adenocarcinoma. Genes \& Dev. 20: 1218-1249.

Hingorani, S.R., Petricoin, E.F., Maitra, A., Rajapakse, V., King, C., Jacobetz, M.A., Ross, S., Conrads, T.P., Veenstra, T.D., Hitt, B.A., et al. 2003. Preinvasive and invasive ductal pancreatic cancer and its early detection in the mouse. Cancer Cell 4: 437-450.

Hingorani, S.R., Wang, L., Multani, A.S., Combs, C., Deramaudt, T.B., Hruban, R.H., Rustgi, A.K., Chang, S., and Tuveson, D.A. 2005. Trp53R172H and KrasG12D cooperate to promote chromosomal instability and widely metastatic pancreatic ductal adenocarcinoma in mice. Cancer Cell 7: 469-483.

Hoshino, M., Nakamura, S., Mori, K., Kawauchi, T., Terao, M., Nishimura, Y.V., Fukuda, A., Fuse, T., Matsuo, N., Sone, M., et al. 2005. Ptfla, a bHLH transcriptional gene, defines GABAergic neuronal fates in cerebellum. Neuron 47: 201213.

Hruban, R.H., Adsay, N.V., Albores-Saavedra, J., Compton, C., Garrett, E.S., Goodman, S.N., Kern, S.E., Klimstra, D.S., Kloppel, G., Longnecker, D.S., et al. 2001. Pancreatic intraepithelial neoplasia: A new nomenclature and classification system for pancreatic duct lesions. Am. J. Surg. Pathol. 25: 579-586.

Hruban, R.H., Adsay, N.V., Albores-Saavedra, J., Anver, M.R., Biankin, A.V., Boivin, G.P., Furth, E.E., Furukawa, T., Klein, A., Klimstra, D.S., et al. 2006. Pathology of genetically engineered mouse models of pancreatic exocrine cancer: Consensus report and recommendations. Cancer Res. 66: 95106.

Jackson, E.L., Willis, N., Mercer, K., Bronson, R.T., Crowley, D., Montoya, R., Jacks, T., and Tuveson, D.A. 2001. Analysis of lung tumor initiation and progression using conditional expression of oncogenic K-ras. Genes \& Dev. 15: 3243-3248.

Janda, E., Lehmann, K., Killisch, I., Jechlinger, M., Herzig, M., Downward, J., Beug, H., and Grunert, S. 2002. Ras and TGF $\beta$ cooperatively regulate epithelial cell plasticity and metastasis: Dissection of Ras signaling pathways. J. Cell Biol. 156: 299-313.

Jemal, A., Siegel, R., Ward, E., Murray, T., Xu, J., Smigal, C., and 
Ijichi et al.

Thun, M.J. 2006. Cancer statistics, 2006. CA Cancer J. Clin. 56: $106-130$.

Kawaguchi, Y., Cooper, B., Gannon, M., Ray, M., MacDonald, R.J., and Wright, C.V. 2002. The role of the transcriptional regulator Ptfla in converting intestinal to pancreatic progenitors. Nat. Genet. 32: 128-134.

Klimstra, D.S. and Longnecker, D.S. 1994. K-ras mutations in pancreatic ductal proliferative lesions. Am. J. Pathol. 145: $1547-1550$.

Lu, S.L., Herrington, H., Reh, D., Weber, S., Bornstein, S., Wang, D., Li, A.G., Tang, C.F., Siddiqui, Y., Nord, J., et al. 2006. Loss of transforming growth factor- $\beta$ type II receptor promotes metastatic head-and-neck squamous cell carcinoma. Genes \& Dev. 20: 1331-1342.

Miyazono, K., ten Dijke, P., and Heldin, C.H. 2000. TGF- $\beta$ signaling by Smad proteins. Adv. Immunol. 75: 115-157.

Offield, M.F., Jetton, T.L., Labosky, P.A., Ray, M., Stein, R.W., Magnuson, M.A., Hogan, B.L., and Wright, C.V. 1996. PDX-1 is required for pancreatic outgrowth and differentiation of the rostral duodenum. Development 122: 983-995.

Oshima, M., Oshima, H., and Taketo, M.M. 1996. TGF- $\beta$ receptor type II deficiency results in defects of yolk sac hematopoiesis and vasculogenesis. Dev. Biol. 179: 297-302.

Rozenblum, E., Schutte, M., Goggins, M., Hahn, S.A., Panzer, S., Zahurak, M., Goodman, S.N., Sohn, T.A., Hruban, R.H., Yeo, C.J., et al. 1997. Tumor-suppressive pathways in pancreatic carcinoma. Cancer Res. 57: 1731-1734.

Sanvito, F., Herrera, P.L., Huarte, J., Nichols, A., Montesano, R., Orci, L., and Vassalli, J.D. 1994. TGF- $\beta 1$ influences the relative development of the exocrine and endocrine pancreas in vitro. Development 120: 3451-3462.

Soriano, P. 1999. Generalized lacZ expression with the ROSA26 Cre reporter strain. Nat. Genet. 21: 70-71.

Venkatasubbarao, K., Ahmed, M.M., Mohiuddin, M., Swiderski, C., Lee, E., Gower Jr., W.R., Salhab, K.F., McGrath, P., Strodel, W., and Freeman, J.W. 2000. Differential expression of transforming growth factor- $\beta$ receptors in human pancreatic adenocarcinoma. Anticancer Res. 20: 43-51.

Wagner, M., Kleeff, J., Friess, H., Buchler, M.W., and Korc, M. 1999. Enhanced expression of the type II transforming growth factor- $\beta$ receptor is associated with decreased survival in human pancreatic cancer. Pancreas 19: 370-376.

Warshaw, A.L. and Fernandez-del Castillo, C. 1992. Pancreatic carcinoma. N. Engl. J. Med. 326: 455-465.

Werlin, S.L. 2004. Exocrine pancreas. In Nelson textbook of pediatrics (ed. R.E. Behrman), pp. 1298-1304. Saunders, St. Louis, MO.

Zavadil, J. and Bottinger, E.P. 2005. TGF- $\beta$ and epithelial-tomesenchymal transitions. Oncogene 24: 5764-5774.

Zhang, H.T., Chen, X.F., Wang, M.H., Wang, J.C., Qi, Q.Y., Zhang, R.M., Xu, W.Q., Fei, Q.Y., Wang, F., Cheng, Q.Q., et al. 2004. Defective expression of transforming growth factor $\beta$ receptor type II is associated with $\mathrm{CpG}$ methylated promoter in primary non-small cell lung cancer. Clin. Cancer Res. 10: 2359-2367.

Zhao, H., Shiina, H., Greene, K.L., Li, L.C., Tanaka, Y., Kishi, H., Igawa, M., Kane, C.J., Carroll, P., and Dahiya, R. 2005. CpG methylation at promoter site -140 inactivates TGF $\beta 2$ receptor gene in prostate cancer. Cancer 104: 44-52. 


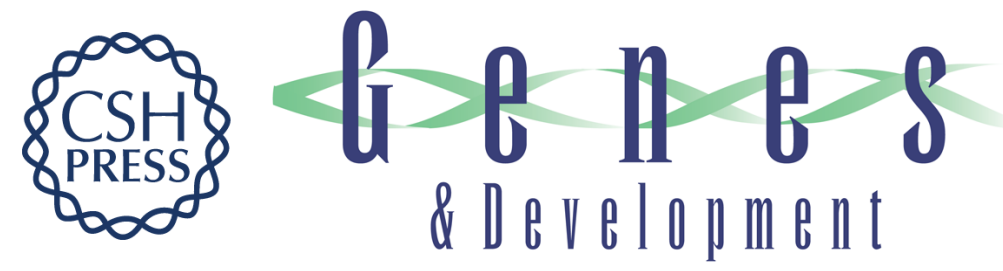

\section{Aggressive pancreatic ductal adenocarcinoma in mice caused by pancreas-specific blockade of transforming growth factor- $\beta$ signaling in cooperation with active Kras expression}

Hideaki ljichi, Anna Chytil, Agnieszka E. Gorska, et al.

Genes Dev. 2006, 20:

Access the most recent version at doi:10.1101/gad.1475506

Supplemental http://genesdev.cshlp.org/content/suppl/2006/10/26/20.22.3147.DC1

Material

References This article cites 37 articles, 16 of which can be accessed free at:

http://genesdev.cshlp.org/content/20/22/3147.full.html\#ref-list-1

License

Email Alerting Receive free email alerts when new articles cite this article - sign up in the box at the top

Service right corner of the article or click here.

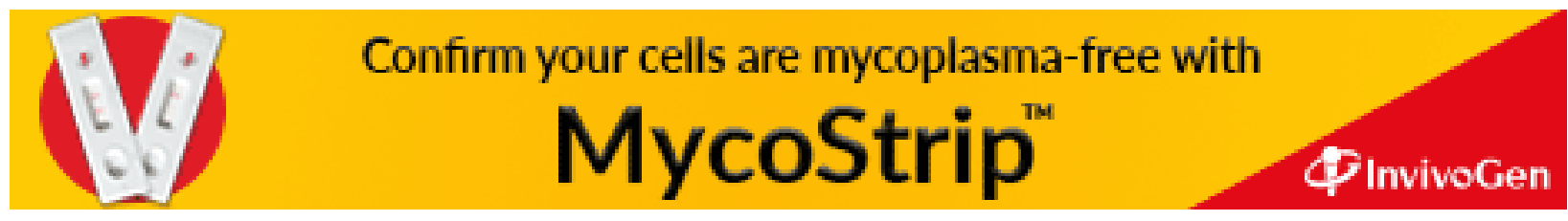

